\title{
Elevator Sizing, Placement, and Control-Relevant Tradeoffs for Hypersonic Vehicles
}

\author{
Jeffrey J. Dickeson * Armando A. Rodriguez ${ }^{\dagger}$ Srikanth Sridharan ${ }^{\ddagger}$ Akshay Korad ${ }^{\S}$
}

\begin{abstract}
Within this paper, control-relevant vehicle design concepts are examined using a widely used 3 DOF (plus flexibility) nonlinear model for the longitudinal dynamics of a generic carrot-shaped scramjet powered hypersonic vehicle. The impact of elevator size and placement on control-relevant static properties (e.g. level-flight trimmable region, trim controls, AOA, thrust margin) and dynamic properties (e.g. instability and right half plane zero associated with flight path angle) are examined. Elevator usage has been examine for a class of typical hypersonic trajectories.
\end{abstract}

\section{INTRODUCTION AND OVERVIEW}

Motivation. With the historic 2004 scramjet-powered Mach 7 and 10 flights of the X-43A ${ }^{1-4}$, hypersonics research has seen a resurgence. This is attributable to the fact that air-breathing hypersonic propulsion is viewed as the next critical step toward achieving (1) reliable, affordable, routine access to space, as well as (2) global reach vehicles. Both of these objectives have commercial as well as military implications. While rocket-based (combined cycle) propulsion systems ${ }^{5}$ are needed to reach orbital speeds, they are much more expensive to operate because they must carry oxygen. This is particularly costly when traveling at lower altitudes through the troposphere (i.e. below 36,152 ft). Current rocket-based systems also do not exhibit the desired levels of reliability and flexibility (e.g. airplane like takeoff and landing options). For this reason, much emphasis has been placed on two-stage-to-orbit (TSTO) designs that involve a turboram-scramjet combined cycle first stage and a rocket second stage. This paper focuses on control challenges associated with scramjet-powered hypersonic vehicles. Such vehicles are characterized by significant aerothermo-elastic-propulsion interactions and uncertainty ${ }^{1-17}$.

Controls-Relevant Hypersonic Vehicle Modeling. The following significant body of work (2005$2009)^{7-9,18-27}$ examines aero-thermo-elastic-propulsion modeling and control issues using a first principles nonlinear 3-DOF longitudinal dynamical model which exploits inviscid compressible oblique shock-expansion theory to determine aerodynamic forces and moments, a 1D Rayleigh flow scramjet propulsion model with a variable geometry inlet, and an Euler-Bernoulli beam based flexible model. The vehicle is $100 \mathrm{ft}$ long with weight (density) $6232 \mathrm{lb}$ per foot of depth and has a bending mode at about $20 \mathrm{rad} / \mathrm{sec}$. The controls include: elevator, stoichiometrically normalized fuel equivalency ratio (FER), diffuser area ratio (not considered in this work), and a canard (not considered in this work). A more complete description of the vehicle model can be found in previous works ${ }^{7,28}$.

More recent modeling efforts have focused on improved propulsion modeling ${ }^{29,30}$ that captures precombustion shocks, dissociation, wall heat transfer, skin friction, fuel-air mixing submodel, and finite-rate chemistry. The computational time associated with the enhanced model is significant, thus making it cumbersome for control-relevant analysis. The simple 1D Rayleigh flow engine model discussed within ${ }^{7,18,25,28}$ will be used in the current paper.

*NASA PhD Fellow, Dept. of Electrical Engineering, Arizona State University, and AIAA Student Member.

${ }^{\dagger}$ Professor, Dept. of Electrical Engineering, Arizona State University, and AIAA Member. This research has been supported, in part, by NASA grant NNX07AC42A.

${ }^{\ddagger}$ MS Student, Dept. of Electrical Engineering, Arizona State University, and AIAA Student Member.

$\S$ MS Student, Dept. of Electrical Engineering, Arizona State University, and AIAA Student Member. 
TSTO Vehicle Trajectory. TSTO launch vehicles consist of a turbo-ram-scramjet combined cycle first stage launch vehicle and a rocket powered orbiter. ${ }^{31}$ A combination of turbo-rocket-ram powered engines propel the craft from the ground to roughly Mach 5. An air-breathing scram-jet engine accelerates the vehicle to Mach 8 along a dynamic pressure of 2000 psf. High dynamic pressures result in better performance for the air-breathing engine. Structural limitations require staging (separation of the launch and orbiter vehicles) to occur at a much lower dynamic pressure, roughly 200 psf. An pull-up maneuver is performed at Mach 8 to increase the altitude until the desired dynamic pressure. After staging, the orbiter vehicle is propelled to low earth orbit by a rocket engine, while the launch vehicle begins a un-powered descent. This work will focus on the altitude pull-up maneuver.

Hypersonic Vehicle Control Issues. Within this paper, we exploit the generic carrot-shaped vehicle 3DOF (plus flexibility) model presented in $[7,18,25,28,32,33]$. A myriad of issues exist that make control design for this hypersonic vehicle a potentially challenging problem:

- Input/Output Coupling. For this system, velocity control is achieved via the FER input. Flight path angle (FPA) control is achieved with the elevator ${ }^{34}$. However, there is significant coupling between $F E R$ and FPA.

- Unstable/Nonminimum Phase. Tail controlled vehicles are characterized by a non-minimum phase (right half plane, RHP) zero that is associated with the elevator to FPA map ${ }^{27}$. This $R H P$ zero limits the achievable elevator-FPA bandwidth $(B W)^{35-37}$. In addition, the rearward situated scramjet and $\mathrm{cg}$ (center of gravity), implies an inherent pitch-up vehicle instability. This instability requires a minimum BW for stabilization ${ }^{28}$. To address these potentially conflicting specifications, one approach has been to exploit the addition of a canard ${ }^{18,34,38-40}$. It is understood, of course, that any canard approach would face severe heating, structural, and reliability issues.

- Varying Dynamic Characteristics. Within ${ }^{28}$, it is shown that the nonlinear model changes significantly as a function of the flight condition. Specifically, it is shown that the vehicle pitch-up instability and non-minimum phase (NMP) zero vary significantly across the vehicle's trimmable region. In addition, the mass of the vehicle can be varied during a simulation in order to represent fuel consumption. Several methods have been presented in the literature to deal with the nonlinear nature of the model.

Papers addressing modeling issues include: nonlinear modeling of longitudinal dynamics ${ }^{27}$, heating effects and flexible dynamics ${ }^{9,23,41}$, FPA dynamics ${ }^{38}$, unsteady and viscous effects ${ }^{8,19}$, and high fidelity engine modeling ${ }^{29,30,42}$.

Papers addressing nonlinear control issues include: control via classic inner-outer loop architecture ${ }^{43}$, nonlinear robust/adaptive control ${ }^{34}$, robust linear output feedback ${ }^{40}$, control-oriented modeling ${ }^{18}$, linear parameter-varying control of flexible dynamics ${ }^{44}$, saturation prevention ${ }^{21,45,46}$, and thermal choking prevention ${ }^{28,46}$.

- Uncertain Flexible Modes and Coupling to Propulsion. Flexible dynamics have been captured within the model by approximating a free-free Euler-Bernoulli beam using the assumed modes method ${ }^{23}$. Three flexible modes are used to approximate the structural dynamics. A damping factor of $\zeta=0.02$ is assumed. The associated mode frequencies are $\omega_{1}=20.94 \mathrm{rad} / \mathrm{sec}, \omega_{2}=50.58 \mathrm{rad} / \mathrm{sec}, \omega_{3}=100.5$ $\mathrm{rad} / \mathrm{sec}$. These modes must be adequately addressed within the control system design process. While performance can be improved by increasing controller complexity (e.g. higher order notches) ${ }^{44}$, one must be wary of, and careful in dealing with, modal/damping uncertainty issues. This is particularly important because structural flexing impacts the bow shock. This, in turn impacts the scramjet's inlet properties, thrust generated, aft body forces, the associated pitching moments, and hence the vehicle's attitude. Given the tight altitude-Mach flight regime - within the air-breathing corridor ${ }^{5}$ - that such vehicle must operate within, the concern is amplified. In short, one must be careful that the control system BW and complexity are properly balanced so that these lightly damped flexible modes are not overly excited.

- Control Saturation Constraints. Control saturation is of particular concern for unstable vehicles such as the one under consideration. Two specific saturation nonlinearities are a concern for any control system implementation. 
- Maximum Elevator/Canard Deflection and Instability. FPA is controlled via the elevator/canard combination $^{38}$. Because these dynamics are inherently unstable, elevator saturation can result in instability ${ }^{45}$. Classical anti-windup methods may be inadequate to address the open loop unstable vehicle. The constraint enforcement method within ${ }^{45,47}$ and generalized predictive control ${ }^{48}$ have been used to address such issues. This paper examines several methods to prevent instability due to elevator saturation. It should be noted that control surface/actuator rate limits must also be properly addressed by the control system in order to avoid instability.

- Thermal Choking/Unity FER: State Dependent Constraint. As heat is added within the combustor, the supersonic air flow is slowed. If enough heat is added, the combustor exit Mach number will approach unity, and the flow is said to be thermally choked ${ }^{49}$. If additional heat is added, the upstream conditions can be altered. This can (in principle) lead to engine unstart ${ }^{5}$ - a highly undesirable condition. The amount of FER that causes thermal choking at a particular flight condition is referred to as the thermal choking FER, or $F E R_{T C}$. In general, $F E R_{T C}$ depends upon the free-stream Mach, free-stream temperature, pressure, and density (which depend on the altitude), and the flow turn angle (vehicle geometry $+\mathrm{AOA}+$ elastic deflection) $^{28,48}$. In addition, since the model does not capture what happens when $F E R \geq 1^{27}$, it is natural to restrict FER below unity. Given the above, it follows that the minimum of these two constraints dictates the available FER at a given flight condition. The resulting state dependent FER constraint can be computed (on-line) based on the flight condition, and must be accounted for by the control law.

Here, uncertainty is of great concern because of the potential unstart issues - issues not captured within the model. Engineers, of course, would try to "build-in protection" so that this is avoided. As such, engineers are forced to tradeoff operational envelop for enhance unstart protection.

Control-Relevant Vehicle Design Issues. Despite the successful integrated approach taken by the X$43 \mathrm{~A}$ team, as well as other prior successful flight control efforts, far too often aerospace vehicle design has not significantly involved the discipline of controls until very late in the vehicle design process or even afterwards. Research programs over the past two decades have suggested that for the anticipated hypersonic vehicles, the traditional "sequential" approach is not likely to work. This is attributable, in part, to complex uncertain nonlinear coupled unstable, non-minimum phase, flexible dynamics together with stringent flight corridor and variable constraints (e.g. specific impulse, fuel use, maximum dynamic pressure, engine temperatures and pressures). For such vehicles, an integrated multidisciplinary "parallel" approach - involving multiple disciplines up front - is essential. This is particularly true when tight flight control specifications must be satisfied in the presence of significant uncertainty.

Goals and Contributions of Paper. This paper addresses a elevator surface issues that are of concern to both vehicle and control system designers. In short, this paper represents a step toward answering the following critical control-relevant vehicle design questions:

1. How do elevator design properties impact a vehicles static and dynamic properties?

2. How do these impact control system design?

3. How should the elevator be designed in the presence of known elevator saturation?

In short, this paper illustrates fundamental tradeoffs that vehicle and control system designers should jointly consider during the early stages of vehicle conceptualization/design. While vehicle designers may want to use a higher fidelity model (e.g. Euler based CFD with boundary layer reconstruction or Navier-Stokes based CFD50) to conduct more accurate vehicle trade studies, this paper shows that a (first principles) 3DOF nonlinear engineering model - such as that used in the paper - may be very useful during the early stages of vehicle conceptualization and design.

Organization of Paper. The remainder of the paper is organized as follows.

- Section II provides an overview of the dynamical model to be used in our studies.

- Section III demonstrates the tradeoffs for elevator surface sizing and placement.

- Section IV outlines the control and guidance architectures used to perform the pull up maneuver.

- Section IV.A contains nonlinear simulations of the pull up maneuver. 
- Section V summarizes the paper and presents directions for future research.

\section{DESCRIPTION OF NONLINEAR MODEL}

In this paper, we consider a first principles nonlinear 3-DOF dynamical model for the longitudinal dynamics of a generic scramjet-powered hypersonic vehicle ${ }^{7-9,18-27}$. The vehicle is $100 \mathrm{ft}$ long with weight (density) 6,154 lb per foot of depth and has a bending mode at about $22 \mathrm{rad} / \mathrm{sec}$. The controls include: elevator, stoichiometrically normalized fuel equivalency ratio (FER), diffuser area ratio (not considered in our work), and a canard (not considered in our work). The vehicle may be visualized as shown in Figure $1^{8}$.

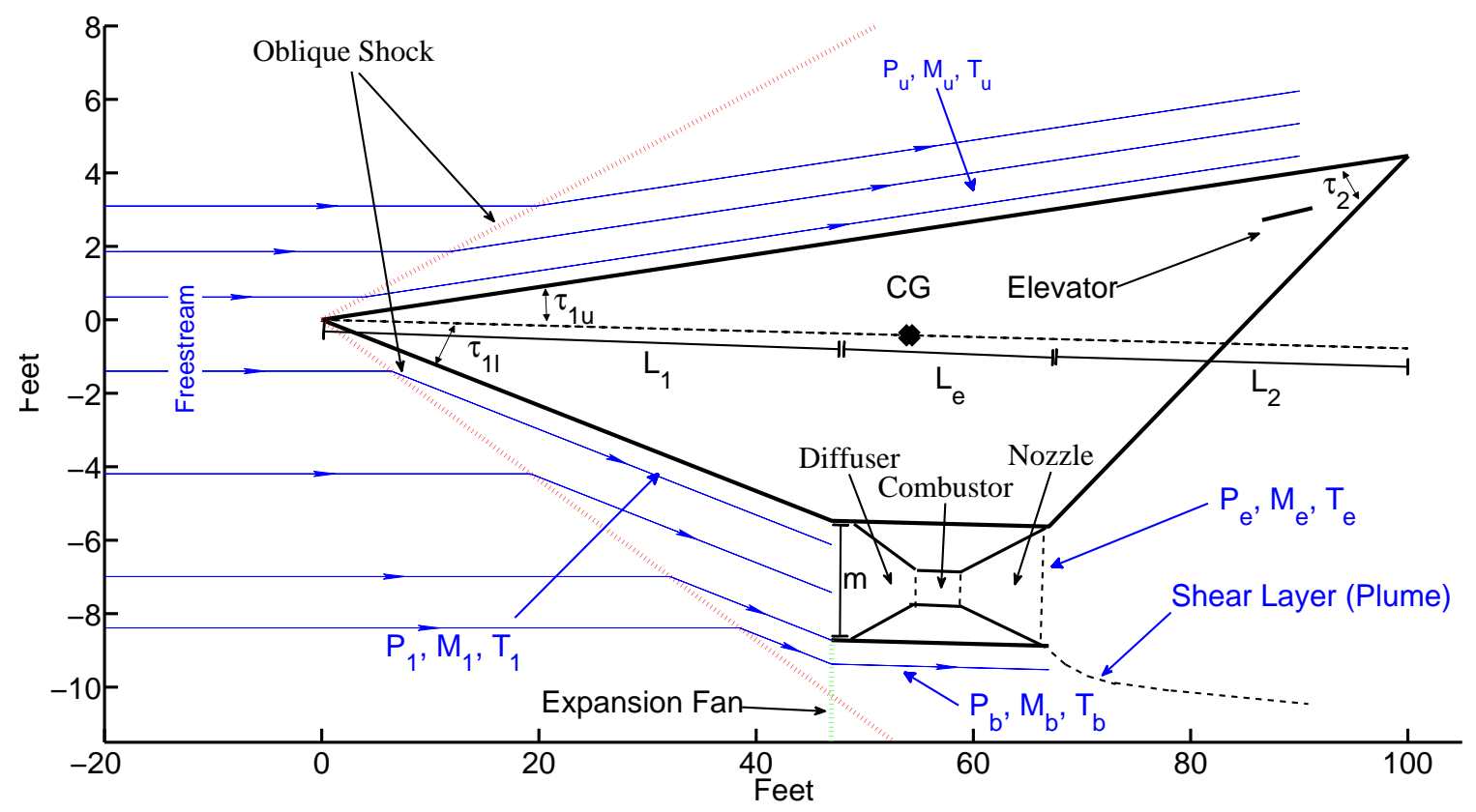

Figure 1. Schematic of Hypersonic Scramjet Vehicle

Modeling Approach. The following summarizes the modeling approach that has been used.

- Aerodynamics. Pressure distributions are computed using inviscid compressible oblique-shock and Prandtl-Meyer expansion theory ${ }^{10,15,27,49}$. Air is assumed to be calorically perfect; i.e. constant specific heats and specific heat ratio $\gamma \stackrel{\text { def }}{=} \frac{c_{p}}{c_{v}}=1.4^{10,49}$. A standard atmosphere is used.

Viscous drag effects (i.e. an analytical skin friction model) are captured using Eckerts temperature reference method ${ }^{8,10}$. This relies on using the incompressible turbulent skin friction coefficient formula for a flat plate. Of central importance to this method is the so-called wall temperature used. The model assumes a nominal wall temperature of $2500^{\circ} R^{8}$.

Unsteady effects (e.g. due to rotation and flexing) are captured using linear piston theory ${ }^{8,50}$. The idea here is that flow velocities induce pressures just as the pressure exerted by a piston on a fluid induces a velocity.

- Propulsion. A single (long) forebody compression ramp provides conditions to the rear-shifted scramjet inlet. The inlet is a variable geometry inlet (variable geometry is not exploited in our work).

The model assumes the presence of an (infinitely fast) cowl door which uses AOA to achieve shockon-lip conditions (assuming no forebody flexing). Forebody flexing, however, results in air mass flow spillage $^{27}$. At the design cruise condition, the bow shock impinges on the engine inlet (assuming no flexing). At speeds below the design-flight condition and/or larger flow turning angles, the cowl moves forward to capture the shock. At larger speeds and/or smaller flow turning angles, the bow shock is swallowed by the engine. In either case, there is a shock reflected from the cowl or within the inlet 
(i.e. we have a bow shock reflection). This reflected shock further slows down the flow and steers it into the engine. It should be noted that shock-shock interactions are not modeled.

The model uses liquid hydrogen (LH2) as the fuel. It is assumed that fuel mass flow is negligible compared to the air mass flow. Thrust is linearly related to FER for all expected FER values. For large FER values, the thrust levels off. In practice, when FER $>1$, the result is decreased thrust. This phenomena ${ }^{27}$ is not captured in the model. As such, control designs based on this nonlinear model (or derived linear models) should try to maintain FER below unity.

The model also captures thermal choking. A (state dependent) saturation level - associated with FER (e.g. thermal choking and unity FER) - and a useful FER margin definition (one that can be used for the design of control systems for scramjet-powered hypersonic vehicles) was addressed $\mathrm{in}^{43}$. Finally, it should be noted that the model offers the capability for addressing linear fuel depletion.

- Structural. A single free-free Euler-Bernoulli beam partial differential equation (infinite dimensional pde) model is used to capture vehicle elasticity. As such, out-of-plane loading, torsion, and Timoshenko effects are neglected. The assumed modes method (based on a global basis) is used to obtain natural frequencies, mode shapes, and finite-dimensional approximants. This results in a model whereby the rigid body dynamics influence the flexible dynamics through generalized forces. Within the current model, forebody deflections influence the rigid body dynamics via the bow shock which influences engine inlet conditions, thrust, lift, drag, and moment ${ }^{23}$. Aftbody deflections influence the AOA seen by the elevator. As such, flexible modes influence the rigid body dynamics.

The nominal vehicle is $100 \mathrm{ft}$ long. The associated beam model is assumed to be made of titanium. It is $100 \mathrm{ft}$ long, 9.6 inches high, and $1 \mathrm{ft}$ wide (deep). This results in the nominal modal frequencies $\omega_{1}=21.02 \mathrm{rad} / \mathrm{sec}, \omega_{2}=50.87 \mathrm{rad} / \mathrm{sec}, \omega_{3}=101 \mathrm{rad} / \mathrm{sec}$. When the height is reduced to 6 inches, then we obtain the following reduced modal frequencies: $\omega_{1}=10.38 \mathrm{rad} / \mathrm{sec}, \omega_{2}=25.13 \mathrm{rad} / \mathrm{sec}$, $\omega_{3}=49.89 \mathrm{rad} / \mathrm{sec}$. Future work will examine vehicle mass-flexibility-control trade studies ${ }^{18}$.

- Actuator Dynamics. Simple first order actuator models (contained within the original model) were used in each of the control channels: elevator $-\frac{20}{s+20}$, FER $-\frac{10}{s+10}$, canard $-\frac{20}{s+20}$ (Note: canard not used in our study). An elevator saturation of $\pm 30^{\circ}$ was used. ${ }^{21,45}$ Elevator position and rate saturation become very important given the vehicle's (open loop) unstable dynamics.

Generally speaking, the vehicle exhibits unstable non-minimum phase dynamics with nonlinear aero-elasticpropulsion coupling and critical (state dependent) FER constraints. The model contains 11 states: 5 rigid body states (speed, pitch, pitch rate, AOA, altitude) and 6 flexible states.

Unmodeled Phenomena/Effects. All models possess fundamental limitations. Realizing model limitations is crucial in order to avoid model misuse. Given this, we now provide a (somewhat lengthy) list of phenomena/effects that are not captured within the above nonlinear model. (For reference purposes, flow physics effects and modeling requirements for the X-43A are summarized within [51].)

- Dynamics. The above model does not capture longitudinal-lateral coupling and dynamics ${ }^{52}$ and the associated $6 \mathrm{DOF}$ effects.

- Aerodynamics. Aerodynamic phenomena/effects not captured in the model include the following: boundary layer growth, displacement thickness, viscous interaction, entropy and vorticity effects, laminar versus turbulent flow, flow separation, high temperature and real gas effects (e.g. caloric imperfection, electronic excitation, thermal imperfection, chemical reactions such as $0_{2}$ dissociation $)^{10}$, non-standard atmosphere (e.g. troposphere, stratosphere), unsteady atmospheric effects ${ }^{6}, 3 \mathrm{D}$ effects, aerodynamic load limits.

- Propulsion. Propulsion phenomena/effects not captured in the model include the following: cowl door dynamics, multiple forebody compression ramps (e.g. three on X-43A ${ }^{53,54}$ ), forebody boundary layer transition and turbulent flow to inlet ${ }^{53,54}$, diffuser losses, shock interactions, internal shock effects, diffuser-combustor interactions, fuel injection and mixing, flame holding, engine ignition via pyrophoric silane $^{3}$ (requires finite-rate chemistry; cannot be predicted via equilibrium methods ${ }^{55}$, finite-rate chemistry and the associated thrust-AOA-Mach-FER sensitivity effects ${ }^{30}$, internal and external nozzle losses, 
thermal choking induced phenomena (2D and 3D) and unstart, exhaust plume characteristics, cowl door dynamics, combined cycle issues ${ }^{5}$.

Within [30], a higher fidelity propulsion model is presented which addresses internal shock effects, diffuser-combustor interaction, finite-rate chemistry and the associated thrust-AOA-Mach-FER sensitivity effects. While the nominal Rayleigh-based model (considered here) exhibits increasing thrustAOA sensitivity with increasing AOA, the more complex model in $^{30}$ exhibits reduced thrust-AOA sensitivity with increasing AOA - a behavior attributed to finite-chemistry effects.

Future work will examine the impact of internal engine losses, high temperature gas effects, and nozzle/plume issues.

- Structures. Structural phenomena/effects not captured in the model include the following: out of plane and torsional effects, internal structural layout, unsteady thermo-elastic heating effects, aerodynamic heating due to shock impingement, distinct material properties, ${ }^{56}$ and aero-servo-elasticity ${ }^{57,58}$.

- Heating-Flexibility Issues. Finally, it should be noted that Bolender and Doman have addressed a variety of effects in their publications. For example, within $[9,23]$ the authors address the impact of heating on (longitudinal) structural mode frequencies and mode shapes. Comprehensive heatingmass-flexibility-control studies will be examined further in a subsequent publication.

- Actuator Dynamics. Future work will examine the impact of actuators that are rate limited; e.g. elevator, fuel pump.

It should be emphasized that the above list is only a partial list. If one needs fidelity at high Mach numbers, then many other phenomena become important; e.g. $\mathrm{O}_{2}$ dissociation ${ }^{10}$.

Longitudinal Dynamics. The equations of motion for the 3DOF flexible vehicle are given as follows:

$$
\begin{aligned}
\dot{v} & =\left[\frac{T \cos \alpha-D}{m}\right]-g \sin \gamma \\
\dot{\alpha} & =-\left[\frac{L+T \sin \alpha}{m v}\right]+q+\left[\frac{g}{v}-\frac{v}{R_{E}+h}\right] \cos \gamma \\
\dot{q} & =\frac{\mathcal{M}}{I_{y y}} \\
\dot{h} & =v \sin \gamma \\
\dot{\theta} & =q \\
\ddot{\eta_{i}} & =-2 \zeta \omega_{i} \dot{\eta}_{i}-\omega_{i}^{2} \eta_{i}+N_{i} \quad i=1,2,3 \\
\gamma & \stackrel{\text { def }}{=} \theta-\alpha \\
g & =g_{0}\left[\frac{R_{E}}{R_{E}+h}\right]^{2}
\end{aligned}
$$

where $L$ denotes lift, $T$ denotes engine thrust, $D$ denotes drag, $\mathcal{M}$ is the pitching moment, $N_{i}$ denotes generalized forces, $\zeta$ demotes flexible mode damping factor, $\omega_{i}$ denotes flexible mode undamped natural frequencies, $m$ denotes the vehicle's total mass, $I_{y y}$ is the pitch axis moment of inertia, $g_{0}$ is the acceleration due to gravity at sea level, and $R_{E}$ is the radius of the Earth.

- States. Vehicle states include: velocity $v, \operatorname{FPA} \gamma$, altitude $h$, pitch rate $q$, pitch angle $\theta$, and the flexible body states $\eta_{1}, \dot{\eta_{1}}, \eta_{2}, \dot{\eta_{2}}, \eta_{3}, \dot{\eta_{3}}$. These eleven (11) states are summarized in Table 1.

- Controls. The vehicle has three (3) control inputs: a rearward situated elevator $\delta_{e}$, a forward situated canard $\delta_{c}{ }^{a}$, and stoichiometrically normalized fuel equivalence ratio (FER). These control inputs are summarized in Table 2. In this paper, we will only consider elevator and FER; i.e. the canard has been removed.

${ }^{\text {a }}$ In this paper, we have removed the canard. Future work will examine the potential utility of a canard as well as its viability. 


\begin{tabular}{|l|c|l|c|}
\hline$\sharp$ & Symbol & Description & Units \\
\hline 1 & $\mathrm{v}$ & speed & $\mathrm{kft} / \mathrm{sec}$ \\
2 & $\gamma$ & flight path angle & $\mathrm{deg}$ \\
3 & $\alpha$ & angle-of-attack (AOA) & $\mathrm{deg}$ \\
4 & $\mathrm{q}$ & pitch rate & $\mathrm{deg} / \mathrm{sec}$ \\
5 & $\mathrm{~h}$ & altitude & $\mathrm{ft}$ \\
6 & $\eta_{1}$ & $1^{\text {st }}$ flex mode & - \\
7 & $\dot{\eta}_{1}$ & $1^{\text {st }}$ flex mode rate & - \\
8 & $\eta_{2}$ & $2^{\text {nd }}$ flex mode & - \\
9 & $\dot{\eta}_{2}$ & $2^{\text {nd }}$ flex mode rate & - \\
10 & $\eta_{3}$ & $3^{\text {rd }}$ flex mode & - \\
11 & $\dot{\eta}_{3}$ & $3^{\text {rd }}$ flex mode rate & - \\
\hline
\end{tabular}

Table 1. States for Hypersonic Vehicle Model

\begin{tabular}{|c|c|l|c|}
\hline$\#$ & Symbol & Description & Units \\
\hline 1 & $F E R$ & stoichiometrically normalized fuel equivalence ratio & - \\
2 & $\delta_{e}$ & elevator deflection & $\mathrm{deg}$ \\
3 & $\delta_{c}$ & canard deflection & $\mathrm{deg}$ \\
\hline
\end{tabular}

Table 2. Controls for Hypersonic Vehicle Model

In the above model, we note that the rigid body motion impacts the flexible dynamics through the generalized forces. As discussed earlier, the flexible dynamics impact the rigid body motion through thrust, lift, drag, and moment. Nominal model parameter values for the vehicle under consideration are given in Table 3 . Additional details about the model may be found within the following references ${ }^{7-9,18-27}$.

\begin{tabular}{|c|c|c|c|}
\hline Parameter & Nominal Value & Parameter & Nominal Value \\
\hline Total Length $(\mathrm{L})$ & $100 \mathrm{ft}$ & Lower forebody angle $\left(\tau_{1 L}\right)$ & $6.2^{\circ}$ \\
Forebody Length $\left(\mathrm{L}_{1}\right)$ & $47 \mathrm{ft}$ & Tail angle $\left(\tau_{2}\right)$ & $14.342^{\circ}$ \\
Aftbody Length $\left(\mathrm{L}_{2}\right)$ & $33 \mathrm{ft}$ & Mass per unit width & $193.7107 \mathrm{slugs} / \mathrm{ft}$ \\
Engine Length & $20 \mathrm{ft}$ & Weight per unit width & $6232.5 \mathrm{lbs} / \mathrm{ft}$ \\
Engine inlet height $\mathrm{h}_{i}$ & $4.5 \mathrm{ft}$ & Mean Elasticity Modulus & $8.6482 \times 10^{7} \mathrm{psi}$ \\
Upper forebody angle $\left(\tau_{1 U}\right)$ & $3^{\circ}$ & Moment of Inertia $\mathrm{I}_{y y}$ & $86,845 \mathrm{slugs} \mathrm{ft}^{2} / \mathrm{ft}$ \\
Elevator position & $(-85,-3.5) \mathrm{ft}$ & Center of gravity & $(-55,0) \mathrm{ft}$ \\
Diffuser exit/inlet area ratio & 0.15 & Elevator Area & $17 \mathrm{ft}{ }^{2}$ \\
Titanium Thickness & $9.6 \mathrm{in}$ & Nozzle exit/inlet area ratio & 6.67 \\
First Flex. Mode $\left(\omega_{n_{1}}\right)$ & $19.7 \mathrm{rad} / \mathrm{s}$ & Second Flex. Mode $\left(\omega_{n_{2}}\right)$ & $47.5 \mathrm{rad} / \mathrm{s}$ \\
Third Flex. Mode $\left(\omega_{n_{3}}\right)$ & $94.4 \mathrm{rad} / \mathrm{s}$ & Flex. Mode Damping $(\zeta)$ & 0.02 \\
\hline
\end{tabular}

Table 3. Vehicle Nominal Parameter Values

\section{Elevator Surface Studies/Design}

The elevator surface is responsible for managing the unstable dynamics of the vehicle. An appropriately designed elevator surface will allow mission maneuvers to be executed while maintaining enough control authority to suppress un-modeled vehicle dynamics and disturbances. An overly large/poorly placed elevator surface will contribute unnecessary drag and add additional weight to the vehicle. The following constraints 
must be considered when sizing/placing the elevator surface:

Elevator Saturation. Elevator constraints such as saturation can result in performance degradation, and possibly instability. ${ }^{45}$ Anti-windup and error governor methodologies may used to maintain stability at the cost of performance. In general it is desirable to design control surfaces such that saturation does not occur for standard maneuvers. Previous works have used saturation levels of $\left[-15^{\circ} 30^{\circ}\right]$ and $\left[-20^{\circ} 20^{\circ}\right]$ for illustrative purposes. ${ }^{48,59}$ Instead of focusing on a particular saturation limit, this paper will attempt to show the tradeoffs in sizing and location for a range of deflection values.

For the altitude pull-up maneuver, elevator usage will be largest due to one of the following scenarios:

1. The dynamic effect of the controller executing the beginning of the maneuver. The size of the elevator deflection will depend upon (1) the magnitude of the FPA command and (2) the elevator-FPA bandwidth.

2. At the lowest dynamic pressure of the maneuver. The pitching moment produced by the elevator is linearly proportional to the dynamic pressure. ${ }^{32,49}$ The 10x decrease in dynamic pressure will need an appropriate increase in elevator deflection to maintain vehicle equilibrium.

Rate Limitation. Rate limitations exist for the elevator due to the hydraulic actuators that manipulate the surface. If the BW associated with these actuators is less than an order of magnitude above the control BW, it should be accounted for in the control design. ${ }^{37}$

Separation. Elevator effectiveness at high speeds and large deflections can be over-predicted by the inviscid/viscous theory due to boundary layer separation. ${ }^{60}$ Tailing edge controls such as an elevator experience separation along the compression side of the surface, reducing the pressure loads. The effective force generated by the surface are unpredictably affected by sudden changes in the pressure magnitude as separation regions form and dissipate. In addition, heat transfer rates can be greatly increased due to vortices within the separated region.

Elevator Effectiveness. Figure 2 show the moment coefficient for the elevator vs the elevator deflection $(\mathrm{AOA}=0)$. The figure can be utilized to determine the increase in effectiveness needed to reduced a particular deflection. For example to reduced a $20^{\circ}$ deflection by $15^{\circ}$ requires a increase in effectiveness by a factor of $57 \%$. This would need to be accomplished through some combination of an increase in elevator surface area and moment arm. Subsections III.A and III.A.2 summarize the effect on the vehicle due to the sizing and placement of the elevator surface in greater detail.

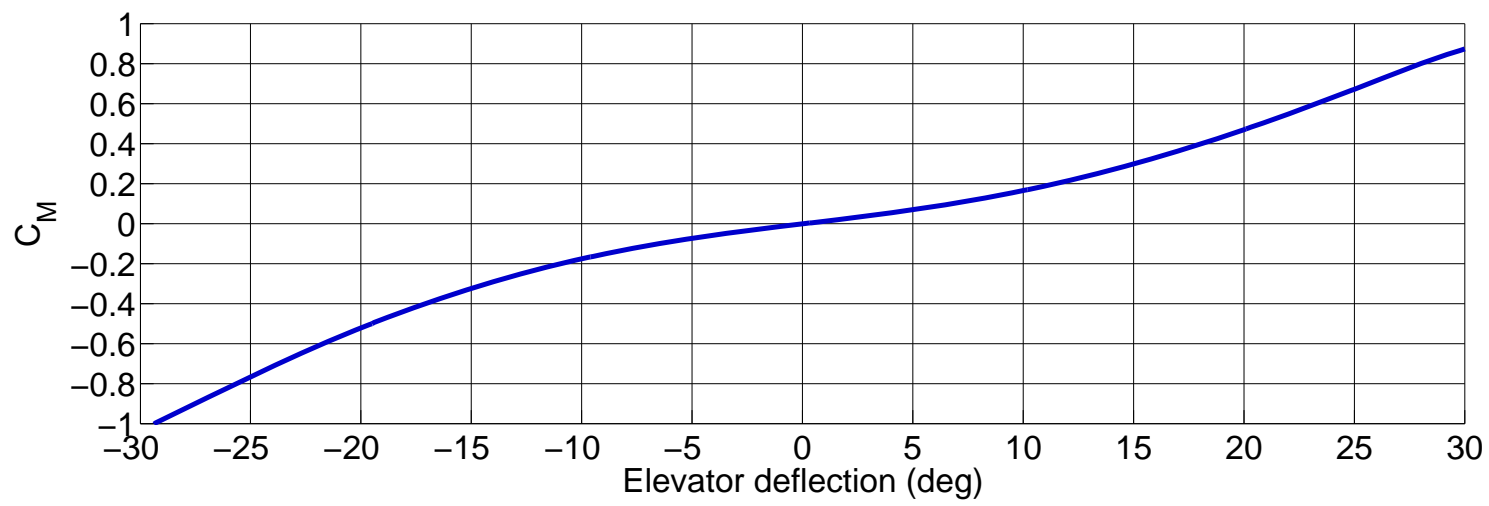

Figure 2. Elevator Moment Coefficient vs Deflection

\section{III.A. Elevator Area}

In this section we examine the impact of varying the elevator surface area. The following assumptions were made: 
- The elevator area is increased in steps of $1.7 \mathrm{ft}^{2}$ from $8.5 \mathrm{ft}^{2}$ to $34 \mathrm{ft}^{2}$.

- The elevator location is fixed at $85 \mathrm{ft}$ from the nose, 3.5 feet above the waterline.

- The weight and structural limitations of the elevator are not modeled.

- The elevator is assumed to be a flat plate; flow separation is not modeled. 


\section{III.A.1. Impact of Elevator Area on Static Properties (Level Flight)}

Trimmable Region. Figure 3 shows how the trimmable region depends upon elevator area.

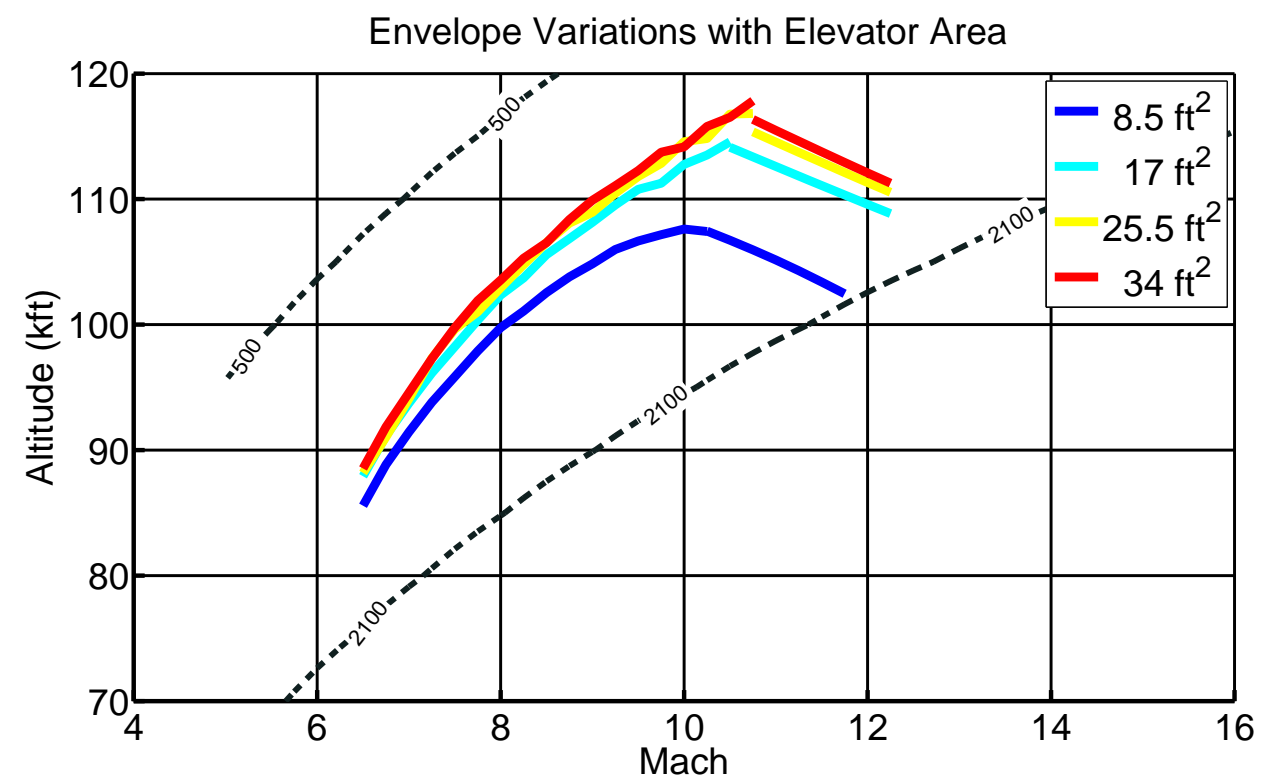

Figure 3. Trimmable Region Dependence on Elevator Area

From Figure 3, the following changes in the trimmable region are apparent:

- The trimmable region shrinks with decreasing elevator area

- The pinch point decreases in Mach and altitude with decreasing elevator area

Trim AOA. Figure 4 shows how the AOA depends upon elevator area. We see that

- Trim AOA is almost independent of the elevator area.
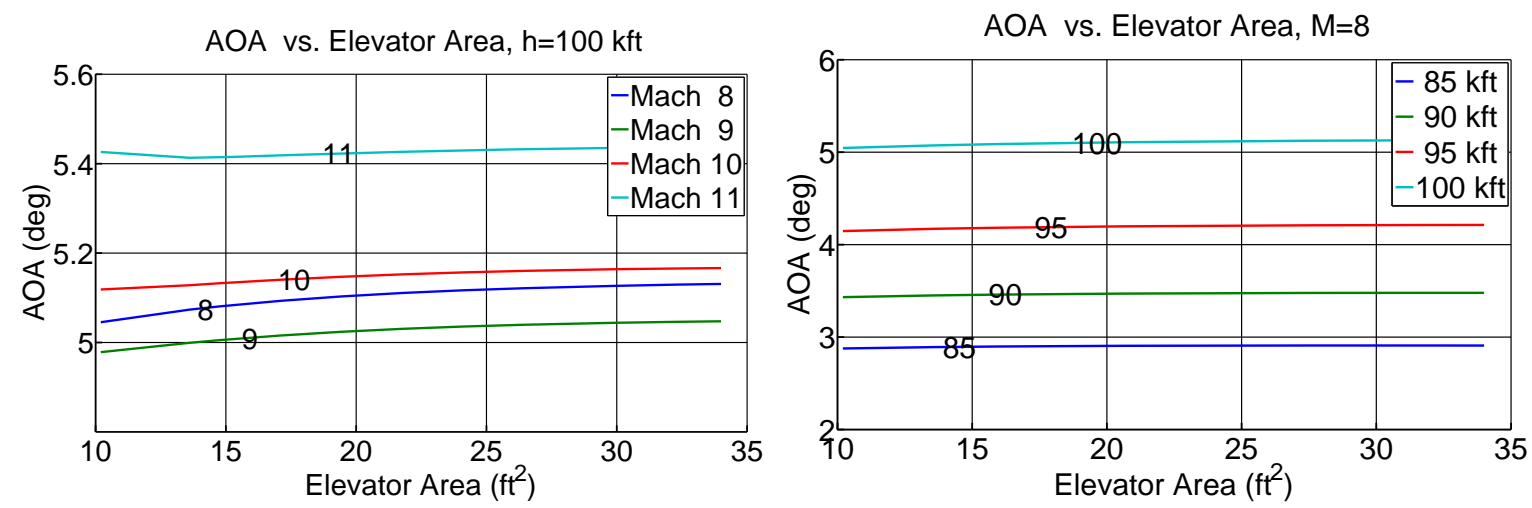

Figure 4. Trim AOA vs Elevator Area

Trim Elevator. Figure 5 shows how trim elevator deflection depends upon elevator area. We observe that

- Trim elevator deflection decreases with increasing elevator area.

- As the elevator area increases, the deflection is weakly dependent on the operating point.

Lift-to-Drag ratio. Figure 6 shows how trim L/D ratio depends upon elevator area. We observe the following: 
Elevator vs. Elevator Area, $\mathrm{h}=100 \mathrm{kft}$

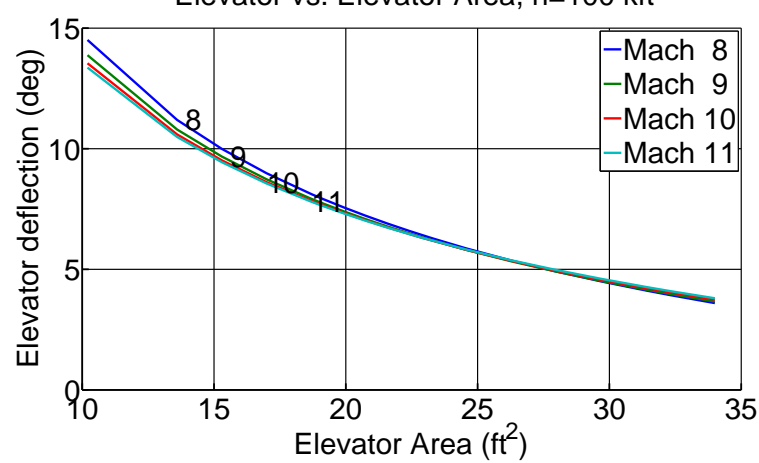

Elevator vs. Elevator Area, $\mathrm{M}=8$

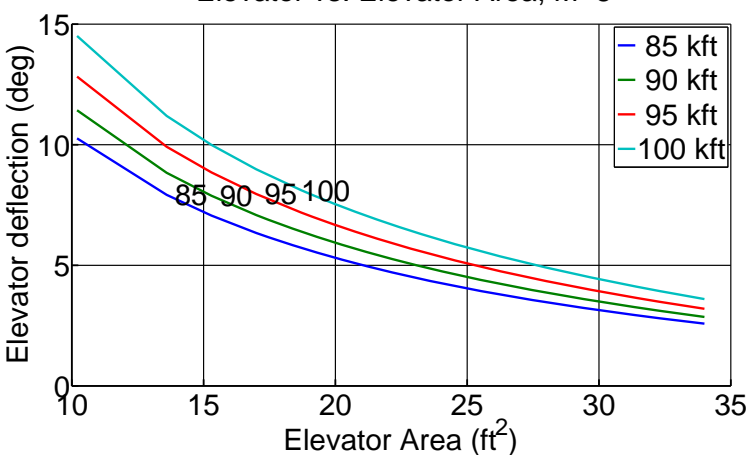

Figure 5. Trim Elevator vs Elevator Area
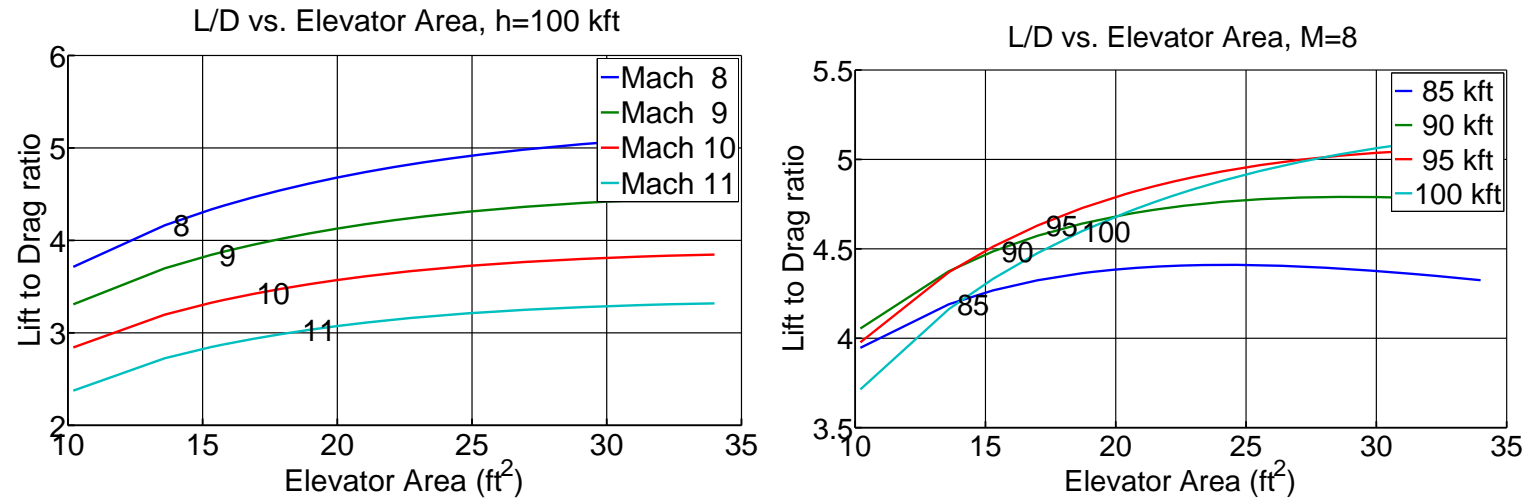

Figure 6. Trim L/D vs Elevator Area

- At lower altitudes, the L/D ratio is concave down with respect to (w.r.t) the elevator area. Figure 5 shows that the elevator deflection decreases with increasing elevator area. The inviscid drag decreases with decreasing elevator deflection (see figure 7). However, the elevator's viscous drag increases. Hence the total elevator drag follows a non-monotonic (concave up) trend w.r.t. elevator area (figure 8).
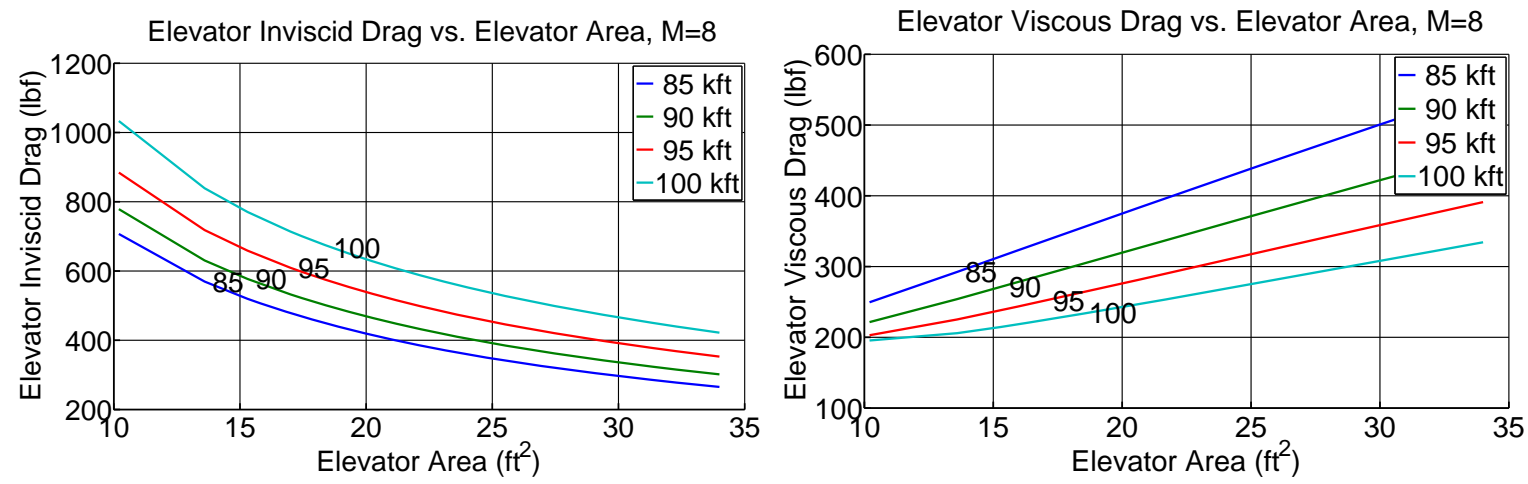

Figure 7. Elevator Drag vs Elevator Area

Trim FER. Figure 9 shows how trim FER depends upon elevator area. From Figure 9, one observes that the:

- Trim FER is non-monotonic (concave up) with increasing elevator area at low altitudes (since total drag is concave up w.r.t. elevator area at low altitudes). 


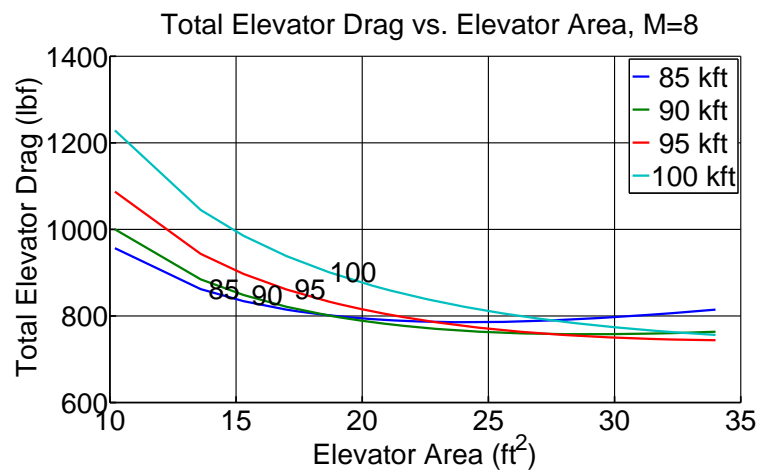

Figure 8. Elevator Drag vs Elevator Area
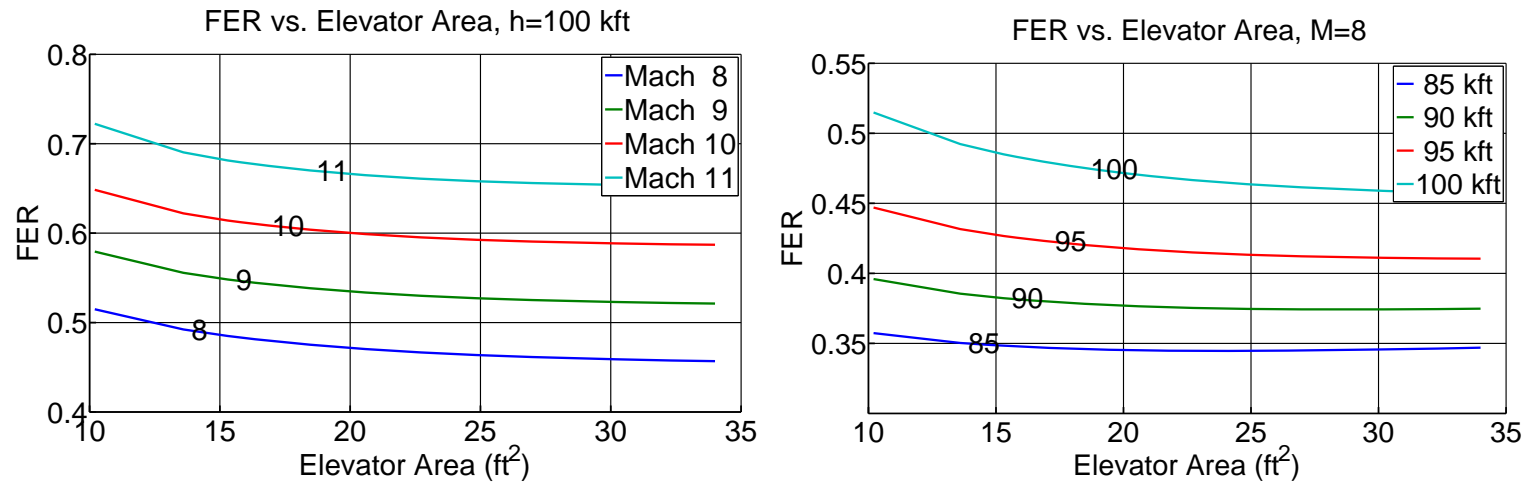

Figure 9. Trim FER vs Elevator Area

\section{III.A.2. Impact of Elevator Area on Dynamic Properties}

Instability. Figure 10 shows how the instability varies with the elevator area. From Figure 10, one observes
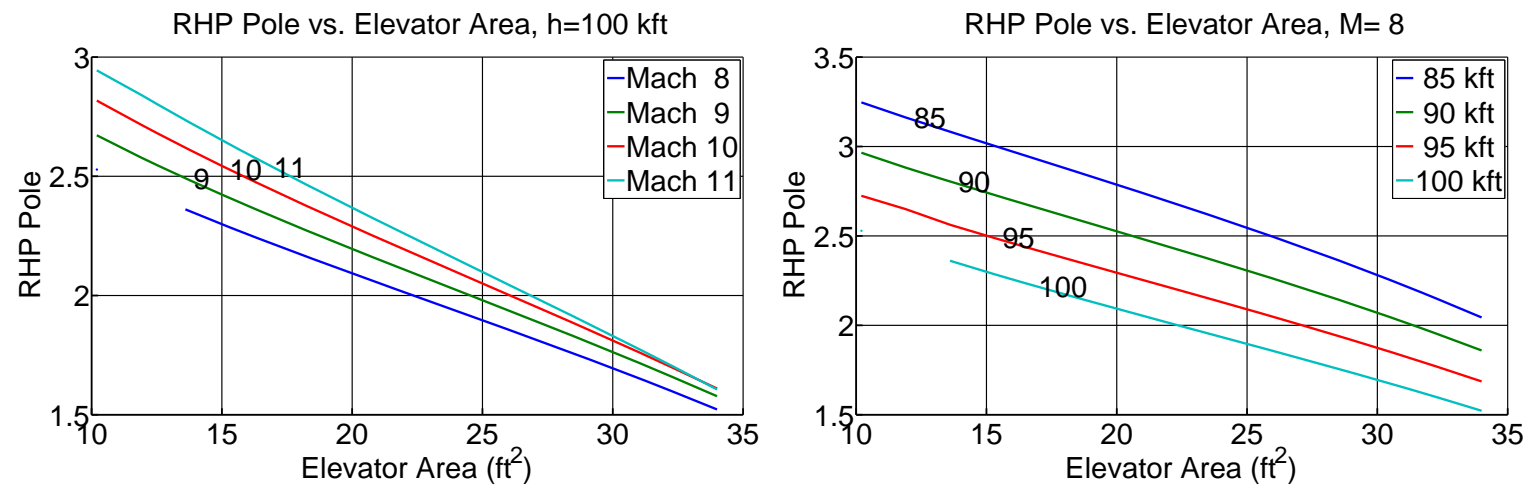

Figure 10. Right Half Plane Pole vs Elevator Area

that the:

- The instability decreases with increasing elevator area - a larger elevator moves the aerodynamic center (ac) rearward, and closer to the center of gravity (cg). As a result, the instability decreases.

- As the elevator area increases, the dependence of the RHP pole on the operating Mach decreases.

RHP Zero. Figure 11 shows how the RHP zero depends varies with the elevator area. From Figure 11, one observes that the:

- RHP Zero remains relatively constant with increasing elevator area 
RHP Zero vs. Elevator Area, $\mathrm{h}=100 \mathrm{kft}$

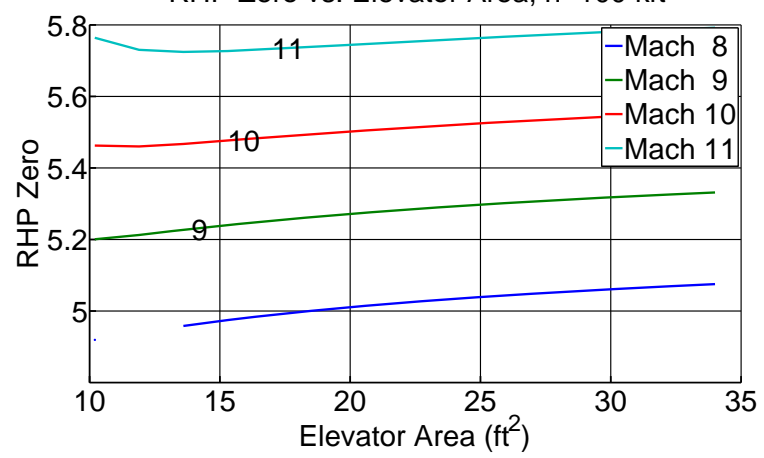

RHP Zero vs. Elevator Area, $M=8$

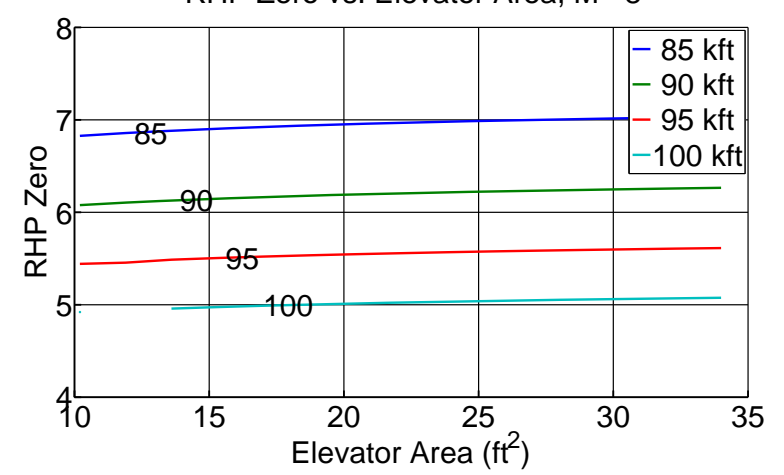

Figure 11. Right Half Plane Zero vs Elevator Area

\section{III.B. Elevator Location}

In this section we examine the impact of moving the elevator rearward w.r.t the the vehicle nose. The following assumptions were made:

- The horizontal elevator location is varied from 70 to $90 \mathrm{ft}$ from the vehicle nose.

- The vertical elevator location is fixed at $2.5 \mathrm{ft}$ above the waterline.

- The elevator area is fixed at $17 \mathrm{ft}^{2}$

- The weight and structural limitations of the elevator are not modeled.

- Elevator is assumed to be a flat plate; flow separation is not modeled.

\section{III.B.1. Impact of Elevator Location on Static Properties}

Trimmable Region. Figure 12 shows how the trimmable region depends upon elevator location. Specifically, we see that the

- Trimmable region expands with as the elevator is moved rearward.

- Pinch point increases with Mach and altitude as the elevator is moved rearward.

Trim AOA. Figure 13 shows how the AOA depends upon elevator location. We see that

- Trim AOA increases as the elevator is moved rearward.

Trim Elevator. Figure 14 shows the variation in trim elevator deflection with a rearward elevator. We observe that the

- Trim elevator deflection decreases as the elevator is moved reward - the elevator moment arm increases, and hence less elevator deflection to provide the same moment.

- As the elevator is moved rearward, the dependence of the trim elevator deflection on Mach decreases.

Lift-to-Drag ratio. Figure 15 shows how trim L/D ratio depends upon elevator location. We observe the following:

- Trim L/D ratio increases as the elevator is moved reward - less elevator deflection for a fixed elevator area results in less drag and higher trim L/D.

FER. From figure 16, we find that the

- Trim FER decreases as the elevator is moved reward - less elevator deflection for a fixed elevator area results in less drag and less trim FER. 


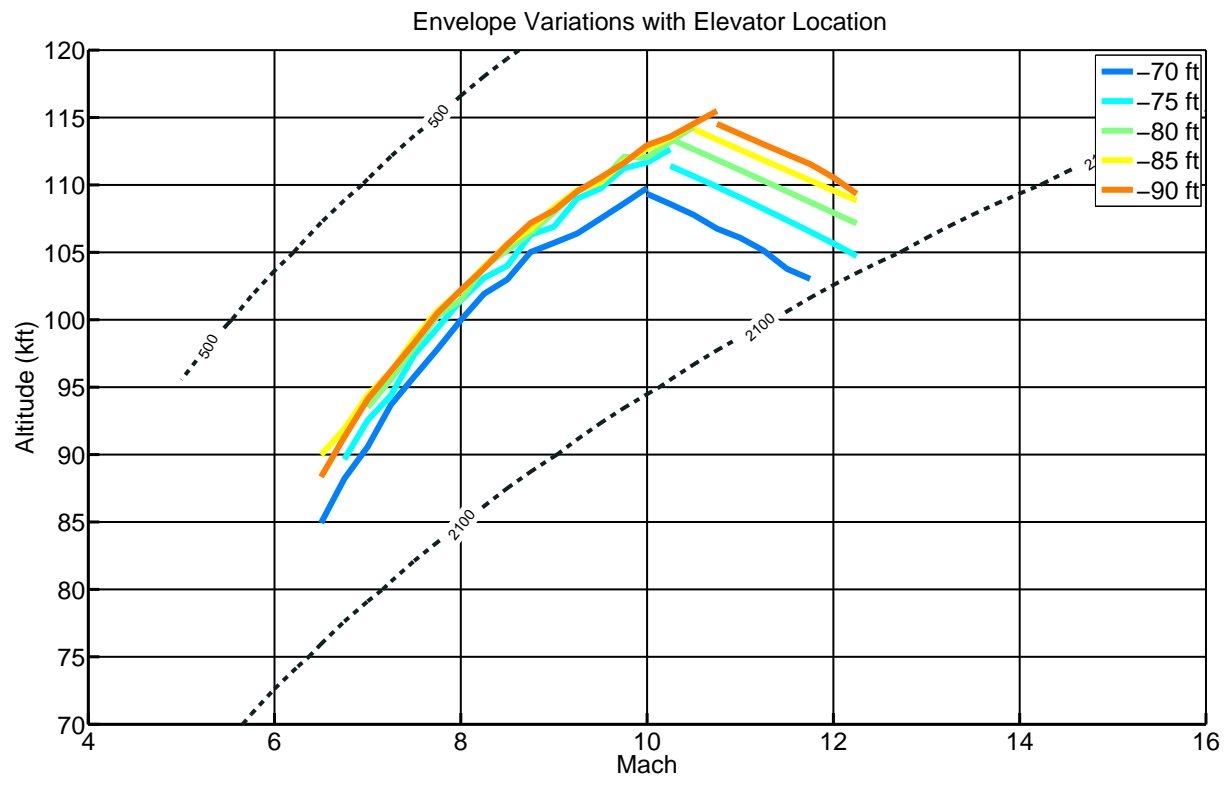

Figure 12. Trimmable Region Dependence on Elevator Location
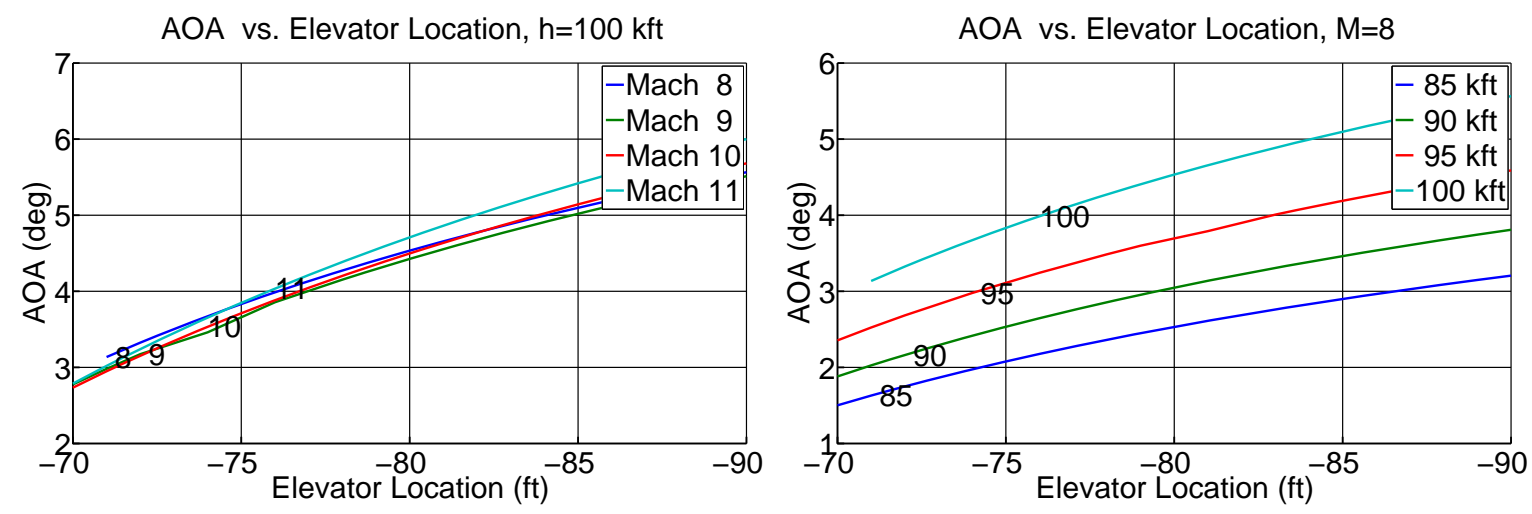

Figure 13. Trim AOA vs Elevator Location
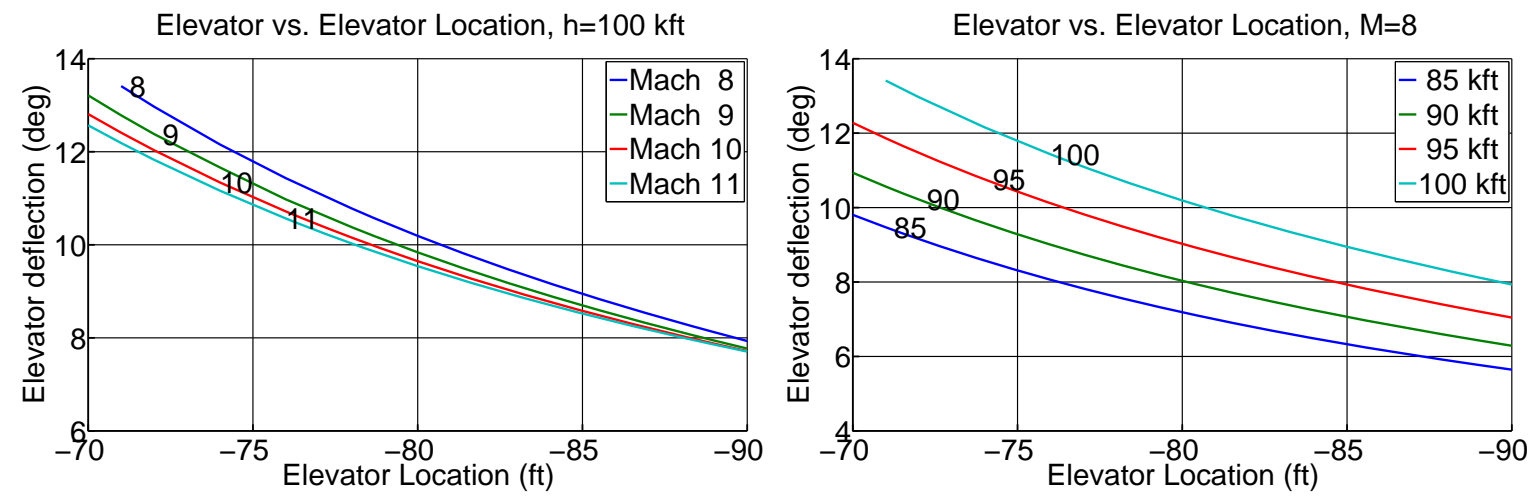

Figure 14. Trim Elevator vs Elevator Location

\section{III.B.2. Impact of Elevator Location on Dynamic Properties}

Instability. Figure 17 shows how the vehicle instability depends upon the elevator location. It is seen that the: 
L/D vs. Elevator Location, $h=100 \mathrm{kft}$

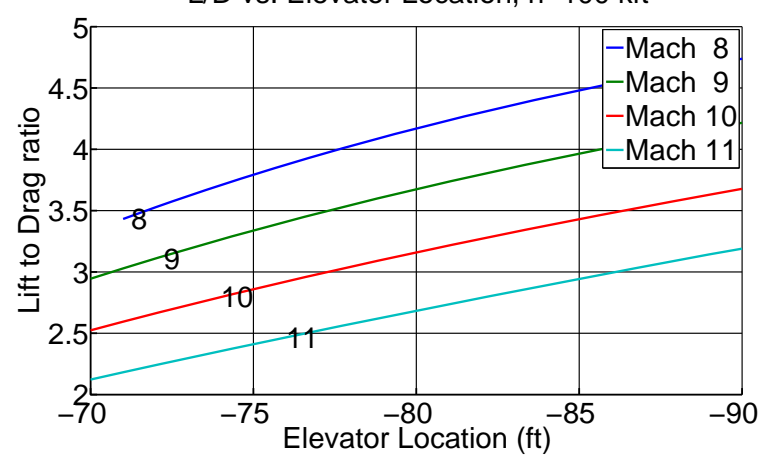

L/D vs. Elevator Location, $M=8$

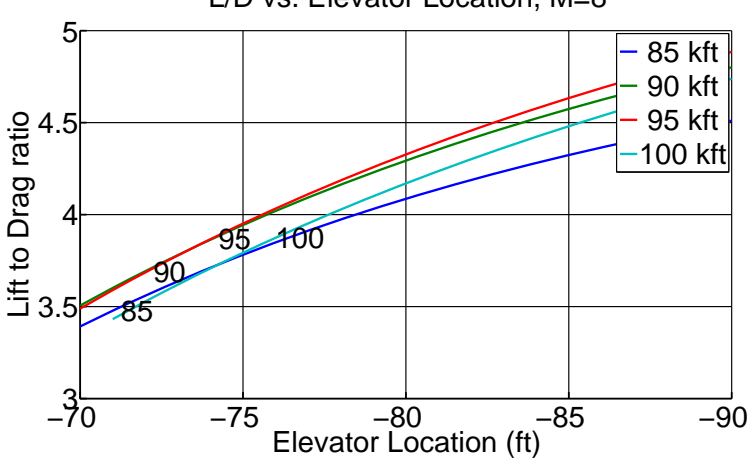

Figure 15. Trim L/D vs Elevator Area
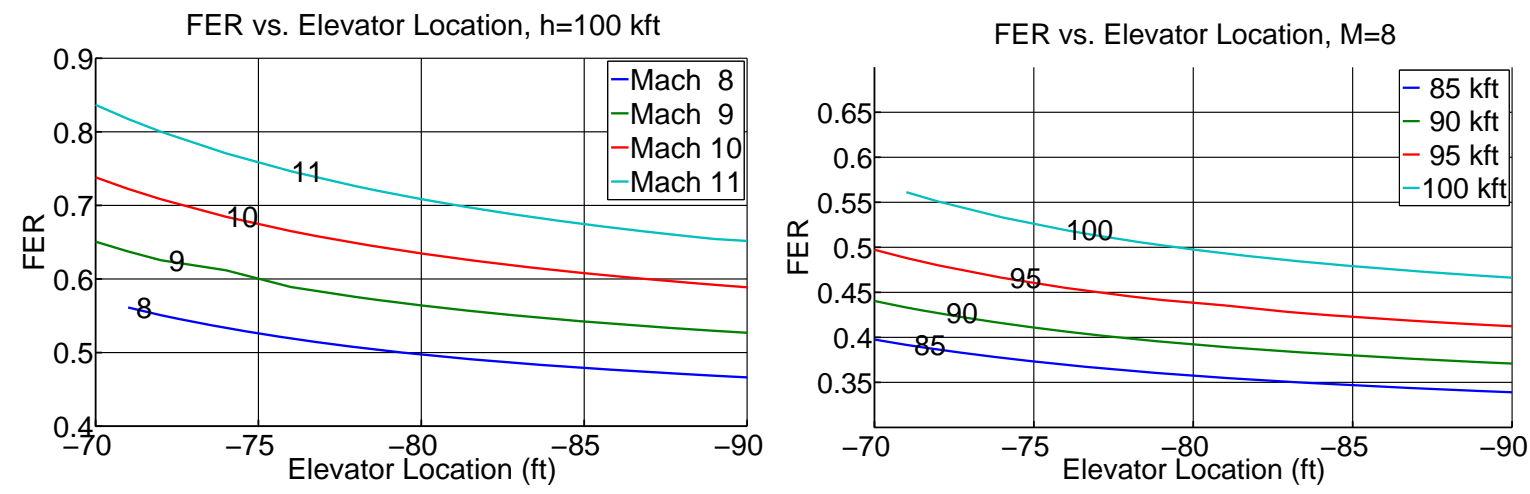

Figure 16. Trim FER vs Elevator Location

- instability decreases linearly as the elevator is moved rearward - the ac moves rearward with the elevator (and closer to the $\mathrm{cg}$ ). As a result, stability imroves.
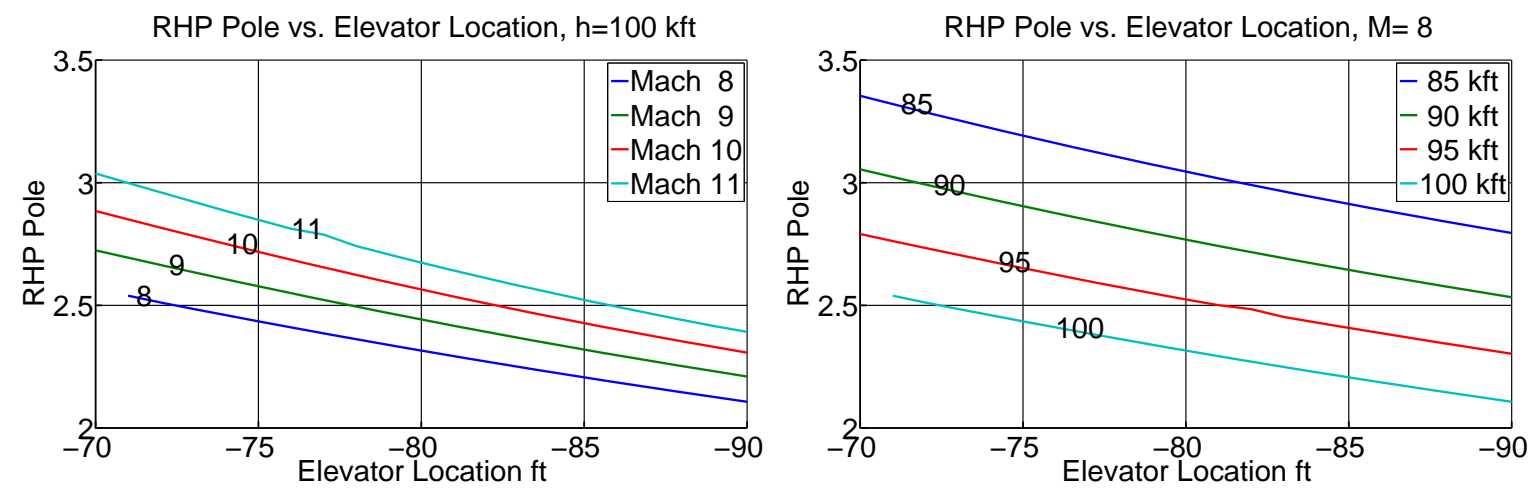

Figure 17. Right Half Plane Pole vs Elevator Location 
RHP Zero. Figure 18 shows how the vehicle instability depends upon the elevator location. From
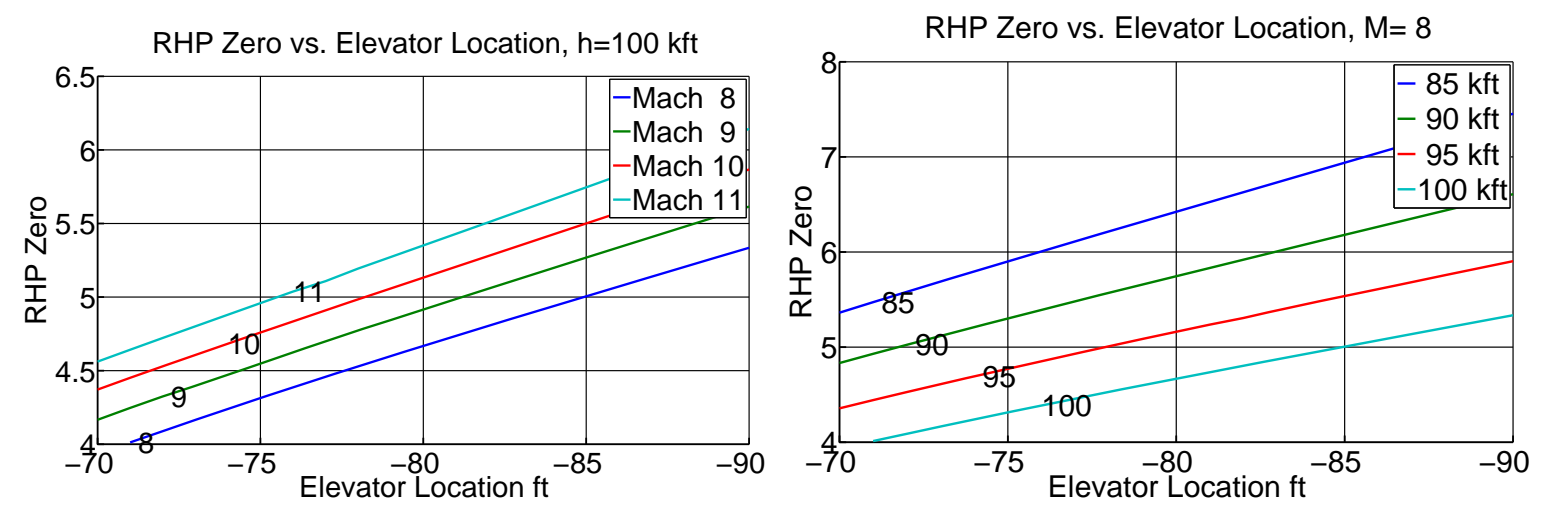

Figure 18. Right Half Plane Zero vs Elevator Location

Figure 18, one observes that the:

- RHP zero increases linearly as the elevator is moved rearward, due to the increasing moment arm of the elevator.

\section{III.C. Summary - Aerodynamic control surface studies}

Elevator Area Increase. Table 4 summarizes trends for increasing elevator areas. ${ }^{61}$ As the elevator area is increased, we observe specific monotonic trends and tradeoffs that result in the following PROS and CONS:

- PROS: trim AOA nearly constant, trim lift remains nearly constant, trim elevator decreases, RHP pole decreases, RHP zero nearly constant.

We also observe the following more complex (non-monotonic) behavior:

- trim lift-to-drag increases (max depends on Mach, altitude) and then decreases;

- trim drag, FER and fuel usage decreases (min depends on Mach, altitude) and then increases.

Table 4. Trends for Increasing Elevator Area

\begin{tabular}{|l|l||l|}
\hline Property & Pro & Con \\
\hline \hline Trim Lift & Almost Constant & Almost Constant \\
Trim Drag (minimizer) & $\uparrow$ with Alt. (fixed Mach) & $\downarrow$ with Mach (fixed Alt.) \\
Trim L/D (maximizer) & $\uparrow$ with Alt. (fixed Mach) & $\downarrow$ with Mach (fixed Alt.) \\
Trim AOA & & Almost Constant \\
Trim Elevator Decreases & & \\
Trim FER (minimizer) & $\uparrow$ with Alt. (fixed Mach) & $\downarrow$ with Mach (fixed Alt.) \\
Trim Fuel Rate (maximizer) & $\uparrow$ with Alt. (fixed Mach) & $\downarrow$ with Mach (fixed Alt.) \\
RHP Pole & Decreases & \\
RHP Zero & & \multirow{2}{|}{ Almost Constant } \\
RHP Z/P Ratio & Increases & \\
\hline
\end{tabular}

Rearward Elevator Shift. Table 5 summarizes trends for varying the elevator location. ${ }^{61}$ As the elevator is moved rearward, we observe specific monotonic trends and tradeoffs that result in the following PROS and CONS:

- PROS: trim L/D, RHP zero and RHP zero-pole ratio increase monotonically. Trim elevator, FER, RHP pole decrease monotonically. 
- CONS: trim AOA, fuel rate increase monotonically.

Non-monotonic patterns are not observed in this case.

Table 5. Trends for Rearward Elevator Shift

\begin{tabular}{|l|l||l|}
\hline Property & Pro & Con \\
\hline \hline Trim Lift & Almost Constant & Almost Constant \\
Trim Drag & Decreases monotonically & \\
Trim L/D & Increases monotonically & \\
Trim AOA & & Increases monotonically \\
Trim Elevator & Decreases monotonically & \\
Trim FER & Decrease monotonically & \\
Trim Fuel Rate & & Increases monotonically \\
RHP Pole & Decreases monotonically & \\
RHP Zero & Increases monotonically & \\
RHP Z/P Ratio & Increases monotonically & \\
\hline
\end{tabular}

\section{Control System}

A classic decentralized inner-outer loop control system architecture was used to illustrate control design issues. Such an architecture was examined within [43]. It can be visualized as shown in Figure 19.

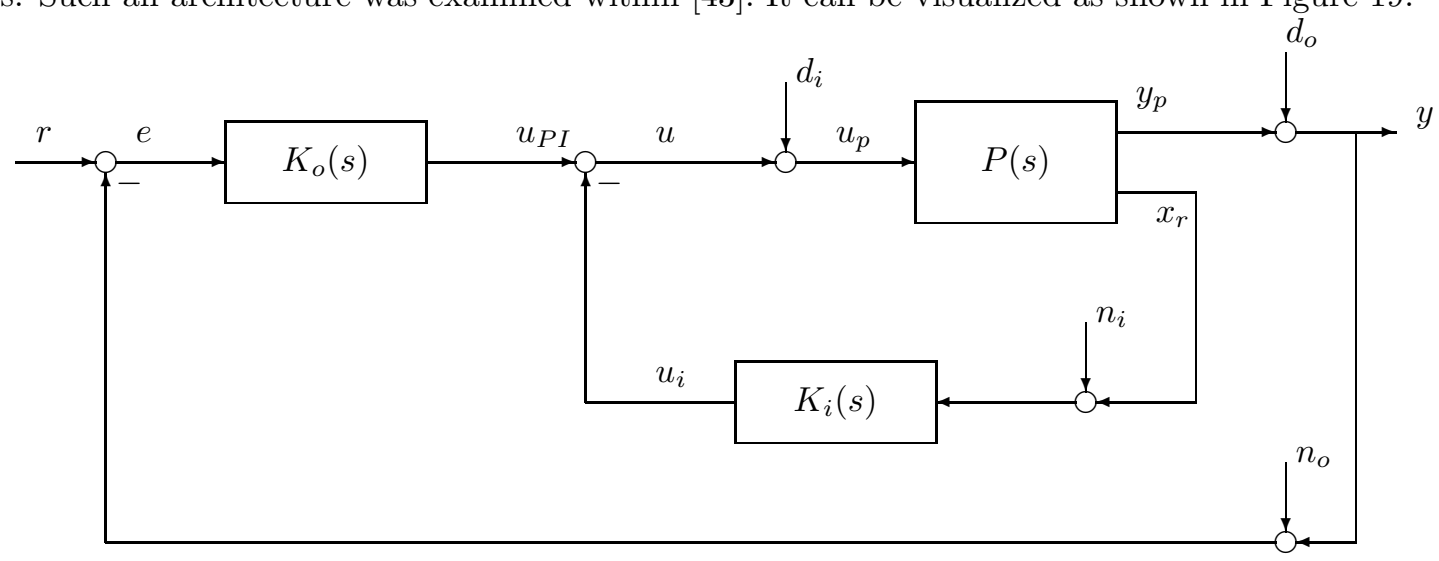

Figure 19. Inner Outer Loop Control System
Outputs: $y_{p}=\left[\begin{array}{ll}v & \gamma\end{array}\right]^{T}$
Controls: $u=\left[\begin{array}{ll}F E R & \delta_{e}\end{array}\right]^{T}$
State Feedback: $x_{r}=\left[\begin{array}{ll}\theta & \dot{\theta}\end{array}\right]^{T}$

Overview of Nominal Control System Architecture. Within Figure 19, we have an inner loop controller:

$$
K_{i}(s)=\left[\begin{array}{cc}
0 & 0 \\
-g_{i} z_{i} \frac{a_{o}}{b_{o}}\left[\frac{s^{2}+b_{1} s+b_{o}}{s^{2}+a_{1} s+a_{o}}\right] & -g_{i} \frac{a_{o}}{b_{o}}\left[\frac{s^{2}+b_{1} s+b_{o}}{s^{2}+a_{1} s+a_{o}}\right]
\end{array}\right]
$$

and an outer loop controller:

$$
K_{o}(s)=\left[\begin{array}{cc}
\frac{g_{b}\left(s+z_{b}\right)}{s}\left[\frac{10}{s+10}\right]^{3} & 0 \\
0 & \frac{g_{\gamma}\left(s+z_{\gamma}\right)}{s}\left[\frac{20}{s+20}\right]^{3}
\end{array}\right]
$$

The inner-outer loop structure is now described. 
1. Velocity Control Via Single Loop PI. A PI controller (with roll off) is used to control velocity. Two parameters are associated with velocity control: $\left(g_{b}, z_{b}\right)$. A simple anti-windup method (not discussed in the paper) is used to address the state-dependent thermal choking nonlinearity discussed earlier.

2. FPA Control Via Inner-Outer Loop. A PD (proportional plus derivative with notch) inner-loop controller is used on pitch to stabilize the vehicle's pitch dynamics and make the modified dynamics look friendly to the outer-loop FPA PI (proportional plus integral) controller. The inner loop's notch provides lead to assist with the first flexible mode's complex zero-pole pair (near $21 \mathrm{rad} / \mathrm{sec}$ ). As might be expected with this inner-outer loop structure, the inner loop is generally much faster than the outer loop. Its bandwidth must be large enough to stabilize the vehicle and follow outer-loop commands, but not too high so that the flexible dynamics are overly excited. (It should be noted that any practical "real-world" implementation of the PD controller should include additional roll off in order to attenuate high frequency noise $n_{i}$ resulting from $\theta$ and theta measurements.)

A PI (proportional plus integral with roll off) outer-loop controller is used for FPA. The outer loop is generally much slower than the inner loop. The maximum achievable outer loop bandwidth is limited by the vehicle's flexible dynamics as well as the right half plane zero associated with the elevator-FPA map.

Four parameters are associated with FPA control: $\left(g_{i}, z_{i}\right)$ for the inner-loop PD controller, $\left.g_{\gamma}, z_{\gamma}\right)$ for the outer-loop PI controller.

Command pre-filters are also included: $W_{b}=\frac{z_{b}}{s+z_{b}}$ for velocity reference commands, $W_{F P A}=\frac{z_{\gamma}}{s+z_{\gamma}}$ for FPA reference commands. (These reference command pre-filters are not shown within Figure 19.)

Additional information about controller parameter selection can be found within [43]. Nominal control system parameter values are given in Table 6.

\begin{tabular}{|c|c|c|c|c|c|c|c|c|c|}
\hline$g_{i}$ & $z_{i}$ & $g_{\gamma}$ & $z_{\gamma}$ & $g_{b}$ & $z_{b}$ & $a_{0}$ & $a_{1}$ & $b_{0}$ & $b_{1}$ \\
\hline 1 & 4.5 & 21.23 & 0.404 & 2.2437 & 0.0278 & 30 & 900 & 15 & 250 \\
\hline
\end{tabular}

Table 6. Control System Parameters for Nominal Hypersonic Vehicle (Mach 8, 85kft, Level Flight)

\section{Overview of Nominal Guidance System Architecture.}

Within this paper, we consider a constant $\bar{q}=2076$ psf flight profile followed by a pull-up maneuver. A guidance system is necessary to issue appropriate FPA commands to maintain a constant dynamic pressure. The complete guidance and flight control systems may be visualized as shown below in Figure 20. The guidance system consists of a PI feedback structure (with roll off):

$$
K_{\text {guidance }}(s)=\left[\frac{k(s+z)}{s}\right]\left[\frac{z_{\gamma}}{s+z_{\gamma}}\right]
$$

where $k=1 / 7846, z=15.7 . z_{\gamma}$ is determined from the outer-loop FPA controller - it is roughly selected to be the FPA outer-loop's PI controller's zero or larger. The second term in brackets is the FPA command pre-filter.

- A simple PI guidance system (which processes dynamic pressure error $e_{\bar{q}}=\bar{q}_{2076 \text { psf }}-\bar{q}_{\text {actual }}$ ) is used to generates FPA guidance commands until Mach 8, $85 \mathrm{kft}$;

- A step velocity reference command is used to take the vehicle along $\bar{q}=2076$ psf from Mach 5.7 at 70 kft to Mach 8 at $85 \mathrm{kft}$.

- Once Mach 8, $85 \mathrm{kft}$ is reached, the pull-up maneuver is executed; FPA commands of increasing magnitude will be compared.

For a more detailed discussion on gain scheduling of the nominal design, see [43]. Within [62] the author also examines gain scheduling issues for the nominal vehicle model. 


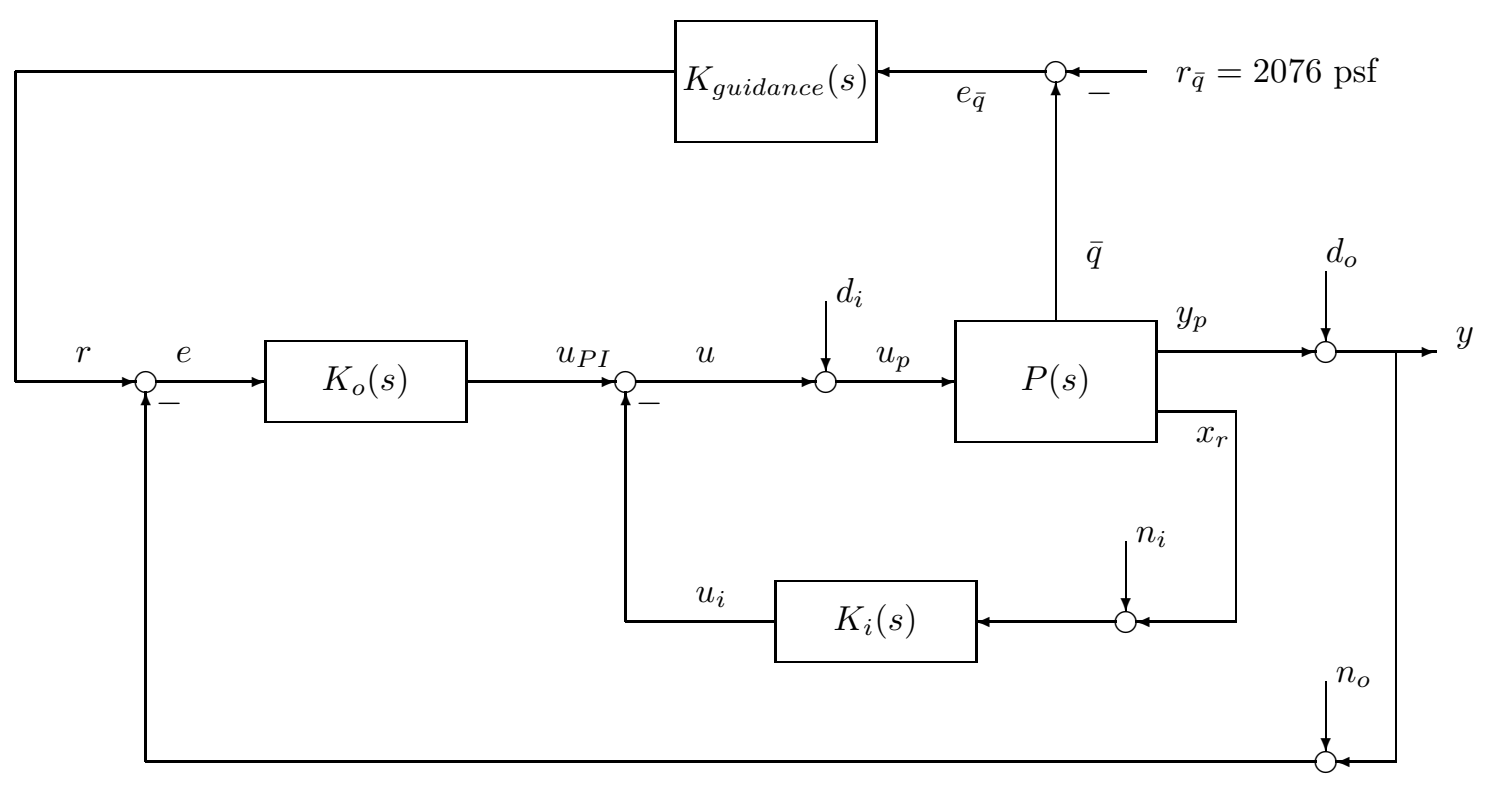

Figure 20. Inner-Outer Loop Architecture and Guidance System

\section{IV.A. Nonlinear Simulation}

Within this section we consider an altitude pull-up maneuver initiated at Mach 8, $85 \mathrm{kft}$. FPA commands magnitudes of $3^{\circ}, 5^{\circ}$, and $7^{\circ}$ have been issued to execute the maneuver. A nominal elevator area of $17 \mathrm{ft}^{2}$ has been chosen. The elevator has been place at $85 \mathrm{ft}$ back from the nose of the vehicle and $3 \mathrm{ft}$ above the water line. The CG of the vehicle is located at approximately $55 \mathrm{ft}$ from the nose of the vehicle along the water line. Important results have been summarized within Table 7.
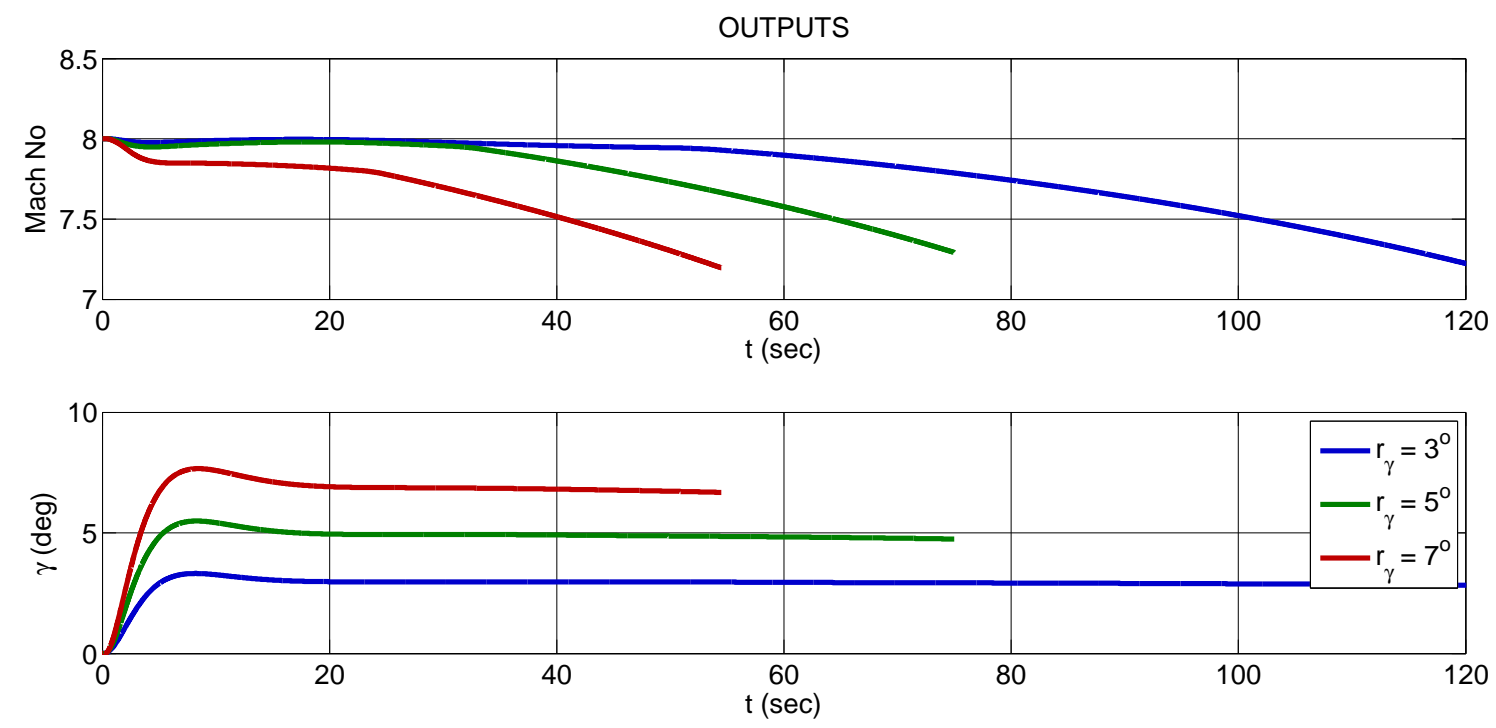

Figure 21. Pull-up Trajectories: Mach and FPA 
Figure 21 shows the Mach number and commanded FPA commands for the 3 trajectories. Mach is commanded to remain at 8 , but cannot be maintained there due to thermal choking limits within the engine ${ }^{28,48}$ as seen in Figure 22.
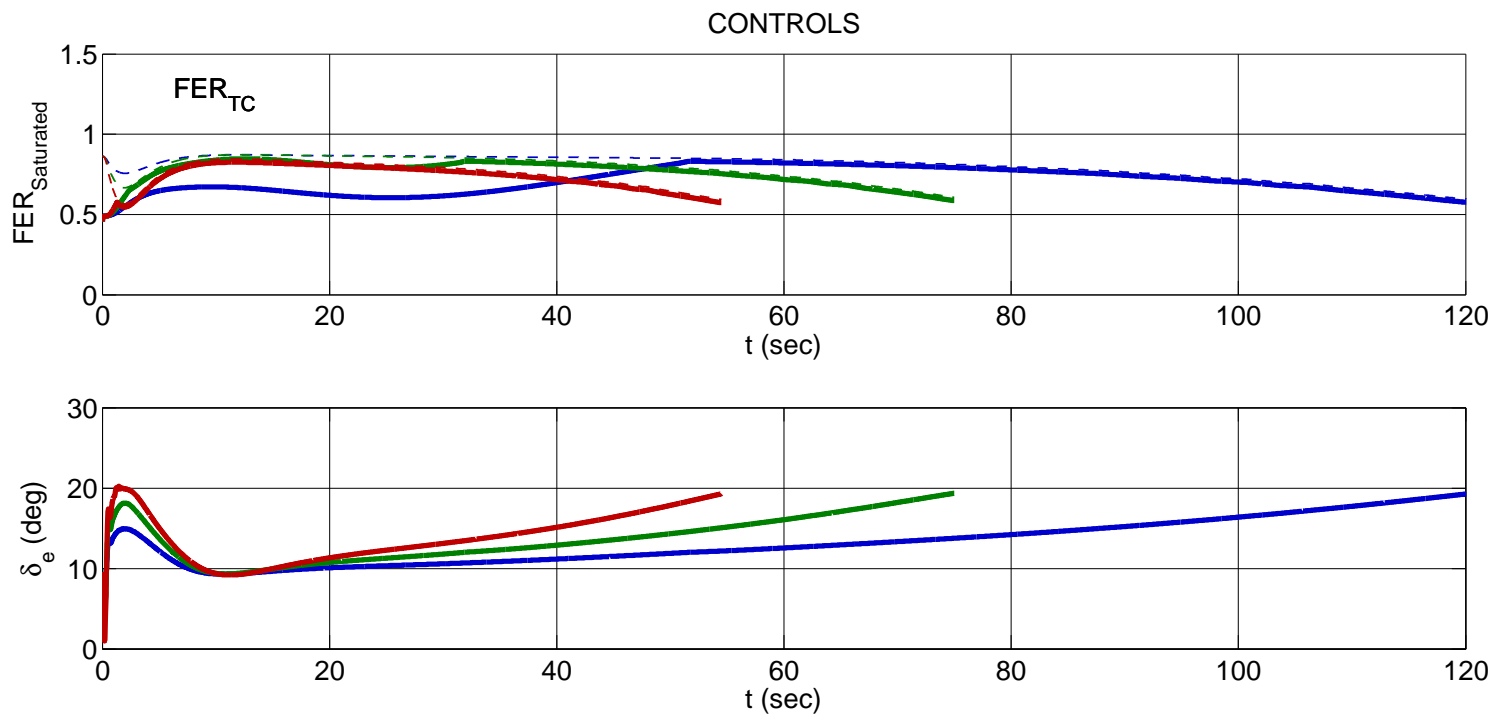

Figure 22. Pull-up Trajectories:Controls

For $3^{\circ}$ and $5^{\circ} \mathrm{FPA}$ commands, a peak elevator usage of $20^{\circ}$ occurs when the vehicle reaches $\bar{q}=200$ psf. If the saturation limit for the elevator was $20^{\circ}$, and a $5^{\circ}$ safety margin was desired for disturbance rejection, then the elevator effectiveness would need to be increased by roughly $57 \%$ as detailed in Section III. For the $7^{\circ}$ (and larger) command, peak elevator usage occurs at the beginning of the pull up maneuver. Peak deflection at this location can be reduced through a combination of improved elevator effectiveness and decreased closed loop bandwidth.

\section{STATES}
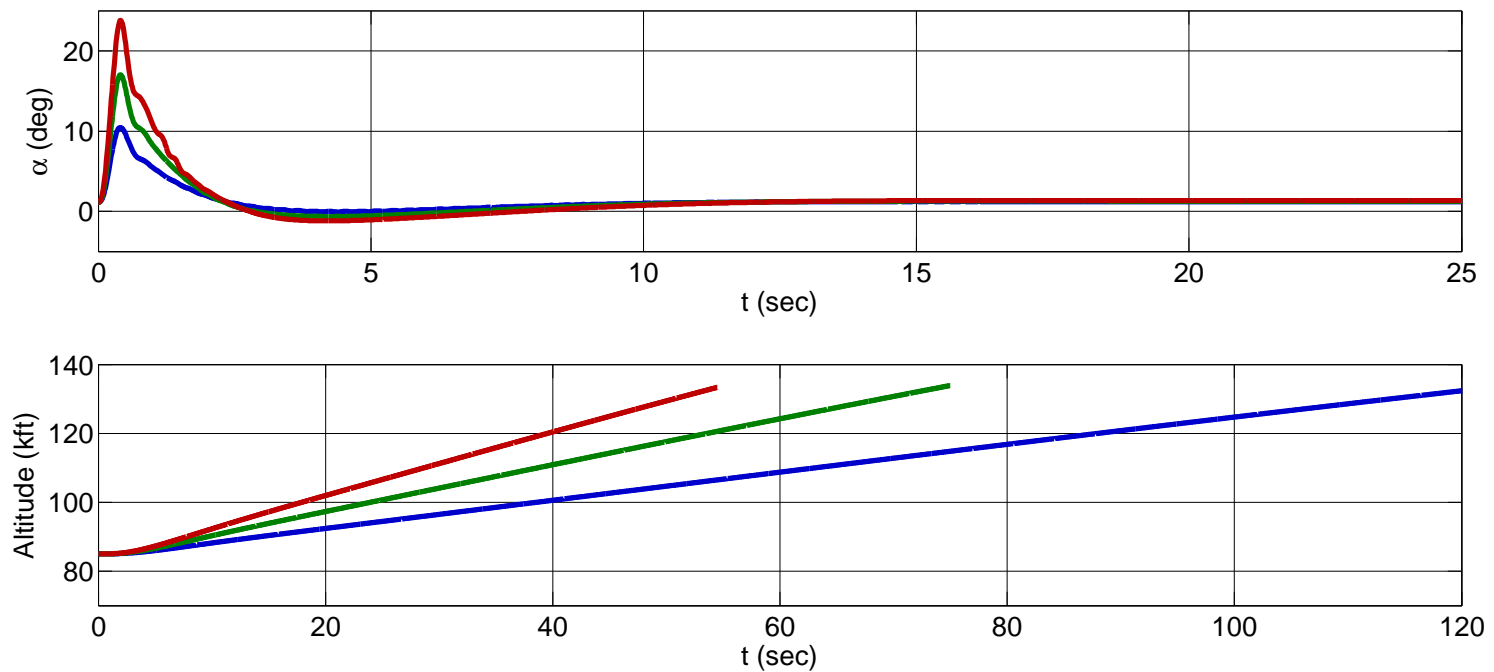

Figure 23. Pull-up Trajectories:AOA and Altitude 
Table 7. Trajectory Properties

\begin{tabular}{|c|c|c|c|}
\hline$\left|r_{\gamma}\right|$ & Duration & Total Fuel Consumption & Initial Peak Elev. Deflection \\
\hline \hline $3^{\circ}$ & $122.1 \mathrm{~s}$ & 4.86 slugs & $14.96^{\circ}$ \\
$5^{\circ}$ & $75.0 \mathrm{~s}$ & 3.79 slugs & $18.14^{\circ}$ \\
$7^{\circ}$ & $54.5 \mathrm{~s}$ & 3.22 slugs & $20.23^{\circ}$ \\
\hline
\end{tabular}

\section{Summary and Directions for Future Work}

Summary and Conclusion. Elevator surface studies have been conducted w.r.t. size and placement. The impact on the vehicles trimmable envelope (region in altitude-Mach space), static (equilibrium) conditions at trim, and dynamic properties as they relate to control system design was addressed for level flight. These studies demonstrates the tradeoffs that can be expected if elevator deflection needs to be decreased due to saturation constraints. Elevator usage has been shown for a family of pull-up trajectories.

Directions for Future Work. Future work will examine the impact of reduced elevator effectiveness due to phenomena such as separation. Anti-windup and error governor will be implemented within the control law to examine their effectiveness during pull-up maneuvers.

\section{Nomenclature}

$\begin{array}{ll}v & \text { true air speed } \\ \alpha & \text { angle of attack (AOA) } \\ \gamma & \text { flight path angle (FPA); not to be confused with specific heat ratio for air } \\ \Theta & \text { pitch angle } \\ q & \text { pitch rate } \\ h & \text { altitude } \\ \eta_{i} & \text { generalized elastic coordinates }(i=1,2,3) \\ \dot{\eta}_{i} & \text { generalized elastic rates }(i=1,2,3) \\ \delta_{e} & \text { elevator deflection } \\ F E R & \text { normalized fuel equivalence ratio }\left(\frac{f}{f_{s t}}\right) \\ \delta & \text { flow deflection angle } \\ \tau_{1 l} & \text { Lower Forebody Wedge Angle }(6.2 \mathrm{deg}) \\ \rho & \text { density of air (standard atmosphere) } \\ \bar{q} & \text { dynamic pressure }\left(\frac{1}{2} \rho v^{2}\right)\end{array}$

\section{References}

${ }^{1}$ E. Baumann, C. Bahm, B. Strovers, R. Beck, and M. Richard, "The X-43A Six Degree of Freedom Monte Carlo Analysis," in 46 ${ }^{\text {th }}$ AIAA Aerospace Sciences Meeting and Exhibit, Paper No. 2008-203, 2008.

${ }^{2}$ C. Peebles, Road to Mach 10: Lessons Learned from the X-43A Flight Research Program. AIAA, 2008.

${ }^{3}$ C. R. McClinton, "X-43 Scramjet Power Breaks the Hypersonic Barrier Dryden Lectureship in Research for 2006," $44^{\text {th }}$ AIAA Aerospace Sciences Meeting and Exhibit, Paper No. 2006-1, 2007.

${ }^{4}$ V. L. Rausch, C. R. McClinton, and J. L. Crawford, "Hyper-X Flight Validation of Hypersonic Airbreathing Technology," Technical Report, NASA Hyper-X Program Office, pp. 1 - 7, 1997.

${ }^{5}$ W. H. Heiser, D. T. Pratt, D. Daley, and U. Mehta, Hypersonic Airbreathing Propulsion. AIAA, 1994.

${ }^{6}$ M. Davis and J. White, "X-43A Flight-Test-Determined Aerodynamic Force and Moment Characteristics at Mach 7.0 ," J. of Spacecraft and Rockets, vol. 45, no. 3, pp. 472-484, 2008.

${ }^{7}$ M. A. Bolender and D. B. Doman, "A Non-Linear Longitudinal Dynamical Model of an Air-Breathing Hypersonic Vehicle," J. Spacecraft and Rockets, vol. 44 no. 2, pp. $373-387,2007$.

${ }^{8} \mathrm{M}$. Bolender, M. Oppenheimer, and D. Doman, "Effects of Unsteady and Viscous Aerodynamics on the Dynamics of a Flexible Air-Breathing Hypersonic Vehicle," in AIAA Atmospheric Flight Mechanics Conf, Es Exhibit, Paper No. $2007-6397$.

${ }^{9}$ M. Bolender and D. Doman, "Modeling Unsteady Heating Effects on the Structural Dynamics of a Hypersonic Vehicle," in AIAA Atmospheric Flight Mechanics Conf. and Exhibit, Paper No. 2006-6646, 2006.

${ }^{10} \mathrm{~J}$. Anderson, Hypersonic and High-Temperature Gas Dynamics. Second Edition. AIAA, 2006. 
${ }^{11}$ S. D. Holland, W. C. Woods, and W. C. Engelund, "Hyper-X Research Vehicle Experimental Aerodynamics Test Program Overview," J. Spacecraft and Rockets, vol. 38, no. 6, pp. 828-835, 2001.

${ }^{12}$ Q. Wang and R. F. Stengel, "Robust Nonlinear Control of a Hypersonic Vehicle," J. Guidance, Control, and Dynamics, pp. $577-585,2000$.

${ }^{13}$ B. Cobleigh, "Development of the X-33 Aerodynamic Uncertainty Model," NASA/TP-1998-206544, April 1998.

${ }^{14} \mathrm{H}$. Buschek and A. Calise, "Uncertainty Modeling and Fixed-Order Controller Design for a Hypersonic Vehicle Model," J. Guidance, Control and Dynamics, pp. $42-48,1997$.

${ }^{15}$ J. J. Bertin, Hypersonic Aerothermodynamics. AIAA Education Series, 1994.

${ }^{16} \mathrm{H}$. Buschek and A. J. Calise, "Robust Control of Hypersonic Vehicles Considering Propulsive and Aeroelastic Effects," Paper No. AIAA-1993-3762, pp. 1 - 11, 1993.

${ }^{17} \mathrm{~J}$. Young and J. Underwood, "Development of Aerodynamic Uncertainties for the Space Shuttle Orbiter ," J. of Spacecraft and Rockets, vol. 20, no. 6, pp. 513-517, 1983.

${ }^{18}$ J. T. Parker, A. Serrani, S. Yurkovich, M. A. Bolender, and D. B. Doman, "Control-oriented modeling of an air-breathing hypersonic vehicle," AIAA J. Guidance, Control, and Dynamics, 2007.

${ }^{19}$ M. Oppenheimer, D. Doman, M. Bolender, and T. Skujins, "A Flexible Hypersonic Vehicle Model Developed with Piston Theory," in AIAA Atmospheric Flight Mechanics Conference and Exhibit, Paper No. 2007-6396, 2007.

${ }^{20}$ D. Doman, M. Oppenheimer, and M. Bolender, "Progress in Guidance and Control Research for Space Access and Hypersonic Vehicles," Air Force Research Laboratory (AFRL), Wright Patterson Air Force Base, pp. 1 - 18, Tech. Rep., 2006.

${ }^{21}$ D. Sigthorsson, A. Serrani, S. Yurkovich, M. Bolender, and D. Doman, "Tracking Control for an Overactuated Hypersonic Air-Breathing Vehicle with Steady State Constraints," in AIAA Guidance, Navigation and Control Conf., Paper No. 2006-6558, 2006.

${ }^{22}$ T. Adami, J. Zhu, M. Bolender, D. Doman, and M. Oppenheimer, "Flight Control of Hypersonic Scramjet Vehicles Using a Differential Algebraic Approach," in AIAA Guidance, Navigation and Control Conf., Paper No. 2006-6559, 2006.

${ }^{23}$ T. Williams, M. A. Bolender, D. Doman, and O. Mortaya, "An Aerothermal Flexible Mode Analysis of a Hypersonic Vehicle," Airforce Research Laboratory (AFRL), Wright Patterson Air Force Base, pp. 1 - 25,, Tech. Rep., 2006.

${ }^{24}$ J. T. Parker, A. Serrani, S. Yurkovich, M. Bolender, and D. Doman, "Approximate feedback linearization of an airbreathing hypersonic vehicle," Air Force Research Laboratory (AFRL), Wright Patterson Air Force Base, pp. 1 - 20, Tech. Rep., 2005.

${ }^{25}$ K. Groves, D. Sigthorsson, A. Serrani, S. Yurkovich, M. Bolender, and D. Doman, "Reference Command Tracking for a Linearized Model of an Air-Breathing Hypersonic Vehicle," in AIAA Guidance, Navigation and Control Conf. and Exhibit, Paper No. 2005-6144, 2005.

${ }^{26}$ K. P. Groves, A. Serrani, S. Yurkovich, M. Bolender, and D. Doman, "Anti-windup control for an air-breathing hypersonic vehicle model," Air Force Research Laboratory (AFRL), Wright Patterson Air Force Base, pp. 1 - 27, Tech. Rep., 2005.

${ }^{27}$ M. A. Bolender and D. B. Doman, "A Non-Linear Model for the Longitudinal Dynamics of a Hypersonic Air-Breathing Vehicle," in Proceedings of the 2005 Guidance, Navigation and Control Conf., Paper No. 2005-6255, 2005.

${ }^{28}$ A. Rodriguez, J. Dickeson, O. Cifdaloz, R. McCullen, J. Benavides, S. Sridharan, A. Kelkar, J. Vogel, and D. Soloway, "Modeling and Control of Scramjet-Powered Hypersonic Vehicles: Challenges, Trends, \& Tradeoffs," in AIAA Conf. on Guidance, Navigation and Control, AIAA-2008-6793, 2008.

${ }^{29} \mathrm{~S}$. Torrez, J. Driscoll, M. Bolender, M. Oppenheimer, and D. Doman, "Effects of Improved Propulsion Modeling on the Flight Dynamic of Hypersonic Vehicles," in AIAA Atmospheric Flight Mechanics Conf. and Exhibit, Paper No. 2008-6386, 2008.

${ }^{30}$ S. Torrez, N. Scholten, J. Driscoll, M. Bolender, M. Oppenheimer, and D. D. Doman, "A Scramjet Engine Model Including Effects of Precomubstions Shocks and Dissociation," in $44^{\text {th }}$ AIAA/ASME/SAE/ASEE Joint Propulsion Conference and Exhibit, Paper No. 2008-6386, 2008.

${ }^{31} \mathrm{~K}$. Shimoyama and K. Sagamihara, "Optimial design of two-stage-to-orbit space planes with airbreathing engines," J. of Spacecraft and Rockets, vol. 42, pp. 90-97, 2005.

${ }^{32}$ J. Dickeson, A. Rodriguez, S. Sridharan, D. Soloway, A. Korad, J. Khatri, J. Benavides, A. Kelkar, and J. Vogel, "Control-relevant modeling, analysis, and design for scramjet-powered hypersonic vehicles," in $16^{\text {th }}$ AIAA/DLR/DGLR Inter. Space Planes and Hyperosnics Sys. and Tech. Conf., AIAA-2009-7287.

${ }^{33}$ J. Dickeson, A. Rodriguez, S. Sridharan, D. Soloway, and J. Benavides, "Decentralized control of an airbreathing scramjetpowered hypersonic vehicle," in AIAA Guidance, Navigation and Control Conf., AIAA-2009-6281.

${ }^{34}$ L. Fiorentini, A. Serrani, M. Bolender, and D. Doman, "Nonlinear Robust/Adaptive Controller Design for an Airbreathing Hypersonic Vehicle Model," in AIAA Guidnace Navigation and Control Conf. and Exhibit, Paper No. 2007-6329, 2007.

${ }^{35}$ G. Stein, "Respect the Unstable," IEEE Control Systems Magazine, August 2003, pp. 12 - 25.

${ }^{36} \mathrm{M}$. W. Oppenheimer and D. B. Doman, "Control of Unstable, Nonminimum Phase Hypersonic Vehicle," in IEEE Aerospace Conf., pp. 5782-5787, 2006.

${ }^{37}$ A. A. Rodriguez, Analysis and Design of Multivariable Feedback Control Systems. Control3D, LLC, 2004.

${ }^{38}$ M. Bolender and D. Doman, "Flight Path Angle Dynamics of Air-Breathing Hypersonic Vehicles," AIAA Guidance Navigation and Control Conf and Exhibit, Paper No. 2006-6692, Tech. Rep., 2006.

${ }^{39}$ P. Jankovsky, D. Sigthorsson, A. Serrani, S. Yurkovich, M. Bolender, and D. Doman, "Output Feedback Control and Sensor Placement for a Hypersonic Vehicle Model," in AIAA Guidance, Navigation and Control Conference and Exhibit, Paper No. AIAA 2007-6327, 2007.

${ }^{40}$ D. Sigthorsson, P. Jankovsky, A. Serrani, S. Yurkovich, M. Bolender, and D. Doman, "Robust Linear Output Feedback Control of an Airbreathign Hypersonic Vehicle," J. of Guidnace, Control and Dynamics, vol. 31, pp. 1-15, 2008.

${ }^{41}$ A. Culler, T. Williams, and M. Bolender, "Aerothermal modeling and dynamic analysis of a hypersonic vehicle," in AIAA Atmospheric Flight Mechanics Conference and Exhibit 2007 Paper. No. 2007-6395, 2007. 
${ }^{42}$ S. Torrez, J. Driscoll, D. Dalle, M. Bolender, and D. Doman, "Hypersonic vehicle thrust sensitivity to angle of attack and mach number," in AIAA Atmospheric Flight Mechanics Conference 2009, Paper No. 2009-6152, 2009.

${ }^{43}$ J. Dickeson, A. Rodriguez, S. Sridharan, J. Benavides, D. Soloway, A. Kelkar, and J. Vogel, "Decentralized control of an airbreathing scramjet-powered hypersonic vehicle," in AIAA Conf. on Guidance, Navigation and Control, AIAA-2009-6281, 2009.

${ }^{44} \mathrm{~S}$. Bhat and R. Lind, "Control-oriented analysis of thermal gradients for a hypersonic vehicle," in Proc. ACC '09. American Control Conference, 10-12 June 2009, pp. 2513-2518.

${ }^{45}$ K. Groves, A. Serrani, S. Yurkovich, M. Bolender, and D. Doman, "Anti-Windup Control for an Air-Breathing Hypersonic Vehicle Model," in AIAA Guidance, Navigation, and Control Conf. and Exhibit, Paper No. AIAA 2006-6557, 2006.

${ }^{46}$ A. Zinnecker, A. Serrani, M. Bolender, and D. Doman, "Combined reference governor and anti-windup design for constrained hypersonic vehicles models," in AIAA Guidance, Navigation, and Control Conference 2009, Paper No. 2009-6283, 2009.

${ }^{47}$ A. Teel and N. Kapoor, "The $\mathcal{L}_{2}$ anti-windup problem: Its definition and solution." in Proc. of the European Control Conf., 1997.

${ }^{48}$ D. Soloway, A. Rodriguez, J. Dickeson, O. Cifdaloz, J. Benavides, S. Sridharan, A. Kelkar, and J. Vogel, "Constraint Enforcement for Scramjet-Powered Hypersonic Vehicles with Significant Aero-Elastic-Propulsion Interactions," in 2009 American Control Conference, Accepted for Publication, 2009.

${ }^{49}$ J. D. Anderson, Modern Compressible Flow, $3^{\text {rd }}$ Edition. McGraw-Hill, 2002.

${ }^{50}$ M. W. Oppenheimer and D. B. Doman, "A Hypersonic Vehicle Model Developed with Piston Theory," in AIAA 20066637, 2006.

${ }^{51}$ C. E. Cockrell, W. C. Englelund, R. D. Bittner, T. N. Jentink, A. D. Dilley, and A. Frendi, "Integrated Aeropropulsive Computational Fluid Dynamics Methodology for the Hyper-X Flight Experiment," J. of Spacecraft and Rockets, pp. 836 - 843 , 2001.

${ }^{52}$ C. Breitsamter, T. Cvrlje, B. Laschka, M. Heller, and G. Sachs, "Lateral-Directional Coupling and Unsteady Aerodynamic Effects of Hypersonic Vehicles," J. Spacecraft and Rockets, pp. 159 - 167, 2001.

${ }^{53}$ S. Berry, K. Daryabeigi, K. Wurster, and R. Bittner, "Boundary Layer Transition on X-43A ," in $38^{\text {th }}$ Fluid Dynamics Conf. and Exhibit, Paper No. 2008-3736, 2008.

${ }^{54}$ S. A. Berry, A. H. Auslender, A. D. Diller, and J. F. Calleja, "Hypersonic Boundary-Layer Trip Development for HyperX," J. Spacecraft and Rockets, pp. $853-864,2001$.

${ }^{55}$ R. Starkey, D. Liu, R. Chang, and P. Chem, "Rapid Conceptual Design and Analysis of a Hypersonic Air-Breathing Missile," in $15^{\text {th }}$ AIAA International Space Planes and Hypersonic Systems and Technologies Conf., 2008-2590, 2008.

${ }^{56}$ D. Glass, "Ceramic Matrix Composite (CMC) Thermal Protection Systems (TPS) and Hot Structures for Hypersonic Vehicles ," in $15^{\text {th }}$ AIAA International Space Planes and Hypersonic Systems and Technologies Conf/, 2008.

${ }^{57}$ D. H. Baldelli, R. Lind, and M. Brenner, "Nonlinear Aeroelastic/Aeroservoelastic Modeling by Block-Oriented Identification," J. Guidance, Control and Dynamics, pp. 1056 - 1064, 2005.

${ }^{58}$ R. Lind and M. Brenner, Robust Aeroservoelastic Stablity Analysis: Flight Test Applications. Springer, 1999.

${ }^{59}$ A. Serrani, A. Zinnecker, L. Fiorentini, M. Bolender, and D. Doman, "Integrated adaptive guidance and control of constrained nonlinear air-breathing hypersonic vehicle models," in 2009 American Control Conf., 2009.

${ }^{60}$ L. Kaufman, S. Hartofilis, E. W, R. Oman, M. L., and D. Weiss, "A review of hypersonic flow separation and control characteristics," Flight Contol Laboratory, United State Air Force, Wright-Patterson Air Force Base, Tech. Rep., ASD TDR $62-168,1962$

${ }^{61}$ S. Sridharan, "Control relevant design of scramjet-powered hypersonic vehicles with aero-thermo-elastic-propulsive effects and uncertainty," Master's thesis, Arizona State University, 2010.

${ }^{62}$ D. Sigthorsson, A. Serrani, M. Bolender, and D. Doman, "Lpv control design for over-actuated hypersonic vehicles models," in AIAA Guidance, Navigation, and Control Conference 2009, Paper No. 2009-6280, 2009. 